\title{
Proteome and Phosphoproteome Changes Associated with Prognosis in Acute Myeloid Leukemia
}

\author{
Elise Aasebø 1,2® , Frode S. Berven 2,3, Sushma Bartaula-Brevik ${ }^{1}$, Tomasz Stokowy ${ }^{1,4}(\mathbb{D}$, \\ Randi Hovland ${ }^{4,5}$, Marc Vaudel ${ }^{1}$, Stein Ove Døskeland ${ }^{3}$, Emmet McCormack ${ }^{6}$, \\ Tanveer S. Batth ${ }^{7}$, Jesper V. Olsen ${ }^{7}$, Øystein Bruserud ${ }^{1}$, Frode Selheim ${ }^{2,3,+}$ and \\ Maria Hernandez-Valladares $1,2, *,+$ \\ 1 Department of Clinical Science, University of Bergen, 5021 Bergen, Norway; Elise.Aasebo@uib.no (E.A.); \\ Sushma.Bartaula@uib.no (S.B.-B.); Tomasz.Stokowy@uib.no (T.S.); Marc.Vaudel@uib.no (M.V.); \\ Oystein.Bruserud@uib.no (Ø.B.) \\ 2 The Proteomics Facility of the University of Bergen (PROBE), University of Bergen, 5009 Bergen, Norway; \\ Frode.Berven@uib.no (F.S.B.); Frode.Selheim@uib.no (F.S.) \\ 3 The Department of Biomedicine, University of Bergen, 5009 Bergen, Norway; stein.doskeland@uib.no \\ 4 Department for Medical Genetics, Haukeland University Hospital, 5021 Bergen, Norway; \\ Randi.Hovland@uib.no \\ 5 Department of Biological Sciences, University of Bergen, 5006 Bergen, Norway \\ 6 Centre for Cancer Biomarkers, Department of Clinical Science, University of Bergen, 5021 Bergen, Norway; \\ Emmet.Mc.Cormack@uib.no \\ 7 Novo Nordisk Foundation Center for Protein Research, University of Copenhagen, \\ 2200 Copenhagen, Denmark; t.batth@cpr.ku.dk (T.S.B.); jesper.olsen@cpr.ku.dk (J.V.O.) \\ * Correspondence: Maria.Hernandez-Valladares@uib.no; Tel.: +47-5558-6368 \\ † F.S. and M.H.-V. share last authorship.
}

Received: 4 February 2020; Accepted: 13 March 2020; Published: 17 March 2020

\begin{abstract}
Acute myeloid leukemia (AML) is a hematological cancer that mainly affects the elderly Although complete remission (CR) is achieved for the majority of the patients after induction and consolidation therapies, nearly two-thirds relapse within a short interval. Understanding biological factors that determine relapse has become of major clinical interest in AML. We utilized liquid chromatography tandem mass spectrometry (LC-MS/MS) to identify the protein changes and protein phosphorylation events associated with AML relapse in primary cells from 41 AML patients at time of diagnosis. Patients were defined as relapse-free if they had not relapsed within a five-year clinical follow-up after AML diagnosis. Relapse was associated with increased expression of RNA processing proteins and decreased expression of V-ATPase proteins. We also observed an increase in phosphorylation events catalyzed by cyclin-dependent kinases (CDKs) and casein kinase 2 (CSK2). The biological relevance of the proteome findings was supported by cell proliferation assays using inhibitors of V-ATPase (bafilomycin), CSK2 (CX-4945), CDK4/6 (abemaciclib) and CDK2/7/9 (SNS-032). While bafilomycin preferentially inhibited the cells from relapse patients, the kinase inhibitors were less efficient in these cells. This suggests that therapy against the upregulated kinases could also target the factors inducing their upregulation rather than their activity. This study, therefore, presents markers that could help predict AML relapse and direct therapeutic strategies.
\end{abstract}

Keywords: acute myeloid leukemia; proteome; phosphoproteome; kinase; V-ATPase; markers; patient relapse; mass spectrometry 


\section{Introduction}

Acute myeloid leukemia (AML) is an aggressive and heterogeneous malignancy, the two main subsets being acute promyelocytic leukemia (APL) and the heterogenous group non-APL AML $[1,2]$. The APL variant is described by a characteristic clinical picture, specific cytogenetic abnormalities, different treatment than the other non-APL variants and a favorable prognosis [3]. In this article, we will use the term AML to refer to the non-APL variants of the disease, and these variants are also highly heterogeneous regarding genetic abnormalities and prognosis (i.e., relapse-free survival), with a median age at the time of first diagnosis of 65-70 years [4]. Despite the heterogeneity of the non-APL variants, these patients are treated according to the same guidelines, both with regard to intensive and potentially curative treatment (possibly including stem cell transplantation) for the young and fit subset of patients and less intensive leukemia-stabilizing treatment for elderly (i.e., above 70-74 years of age) or unfit patients [4-6]. Most patients receiving intensive anti-AML treatment achieve initial disease control (i.e., complete hematological remission), but a major cause of death is due to primary resistance and chemoresistant leukemia relapse either during or following the chemotherapy $[4,5,7]$. The overall long-term AML free survival, even for young and fit AML patients, is therefore only approximately $50 \%$ [8]. Thus, there is a need for a better prognostic classification and therapeutic strategies both for the younger patients receiving intensive therapy and for the large majority of elderly or unfit patients receiving leukemia-stabilizing therapy.

Even though previous studies have detected associations between prognosis and the phosphorylation status of selected intracellular mediators [9,10], only cytogenetic abnormalities and submicroscopic mutations of certain genes (e.g., in CEBPA, FLT3, NPM1 and TP53) are implemented in the routine prognostic evaluation and risk adapted treatment of AML patients procedures [8,11-15]. However, the underlying of AML relapse determinants remains elusive, as most of the late relapse cases are associated with a normal karyotype or with the absence of typical cytogenetic abnormalities observed in therapy-related AML [16,17]. Mutations in NPM1 and in signaling genes such as NRAS, KIT and PTPN11 are frequently observed at time of diagnosis but are less found at relapse [18,19]. However, FLT3-ITDs and mutations in WT1, KDM6A and RUNX1 are often found at relapse [8,20]. Although epigenetic regulation might be necessary for the development of relapse, regulators of DNA methylation and of chromatin remodeling as well as histone modifiers show different evolutionary patterns from diagnosis to relapse stages [21]. A separate longitudinal genomic characterization has shown that in $80 \%$ of the patients, the founder leukemic clone survived chemotherapy and provide a basis for late relapse [22].

Liquid chromatography tandem mass spectrometry (LC-MS/MS)-based proteomics or phosphoproteomics have been utilized for the subclassification of patients with non-APL variants of AML [23-25] and for the study of proteins released by apoptosis-resistant and sensitive primary AML cells [26]. Remarkable advances in the mass spectrometry technology over the past decades have provided equipment with optimized resolution, allowing high coverage characterizations of post-translation modifications (PTMs). Thus, predictive phosphorylation markers for the treatment of AML with FLT3 inhibitor quizartinib, the description of the phosphotyrosine-proteome, tyrosine-kinome and tyrosine-phosphatome in AML, and the identification of sensitivity determinants of AML cells to kinase inhibitors have been recently described [27-29].

We previously showed that a super-SILAC (Stable Isotope Labeling with Amino Acids in Cell Culture) mix based on five AML cell lines provided a solid reference for quantitative proteomics studies of AML patient cells [30]. Together with optimized sample preparation and phosphopeptide enrichment protocols, our proteomics workflows proved to be useful for the study of prognosis biomarkers and treatment response in AML [31-33].

In the present population based-study, in order to identify relapse promoters at diagnosis, we compared the proteome and phosphoproteome profiles of pretreatment AML cells collected at the time of diagnosis for patients who later became long-term leukemia-free survivors (at least 5 years AML-free survival), or had a primary resistant disease, or suffered from a chemoresistant relapse after completing 
the planned intensive therapy. Based on the proteomics and phosphoproteomics analysis of these two groups, we found common denominators in pretreatment samples such as RNA processing and V-ATPase proteins, that should be further investigated as potential prognostic biomarkers or possible therapeutic targets.

\section{Results}

\subsection{AML Patients Included in the Study}

To study the proteome and phosphoproteome changes between chemoresistant/relapse (RELAPSE) and relapse-free (REL_FREE) patients at the time of first diagnosis, we selected 41 patient samples, as illustrated in Figure 1a,b. The main characteristics of our patient cohort are given in Table 1 and Table S1. As expected, approximately half of the 41 patients showed a normal karyotype (22 out of 36 investigated patients); the most common mutations were on NPM1 and FLT3-ITD (Table S1). Furthermore, when analyzing the whole patient cohort, NPM1 mutations showed significant correlations both with morphological signs of AML cell differentiation (especially FAB M4/M5; Fischer's exact test, $p=0.023$ ) and DNA methylation gene mutations $(p=0.003)$. All these observations are consistent with observations previously described for AML in general [4,12-14]. Finally, the percentage of bone marrow AML blasts did not differ between the two subsets $(p=0.247)$.
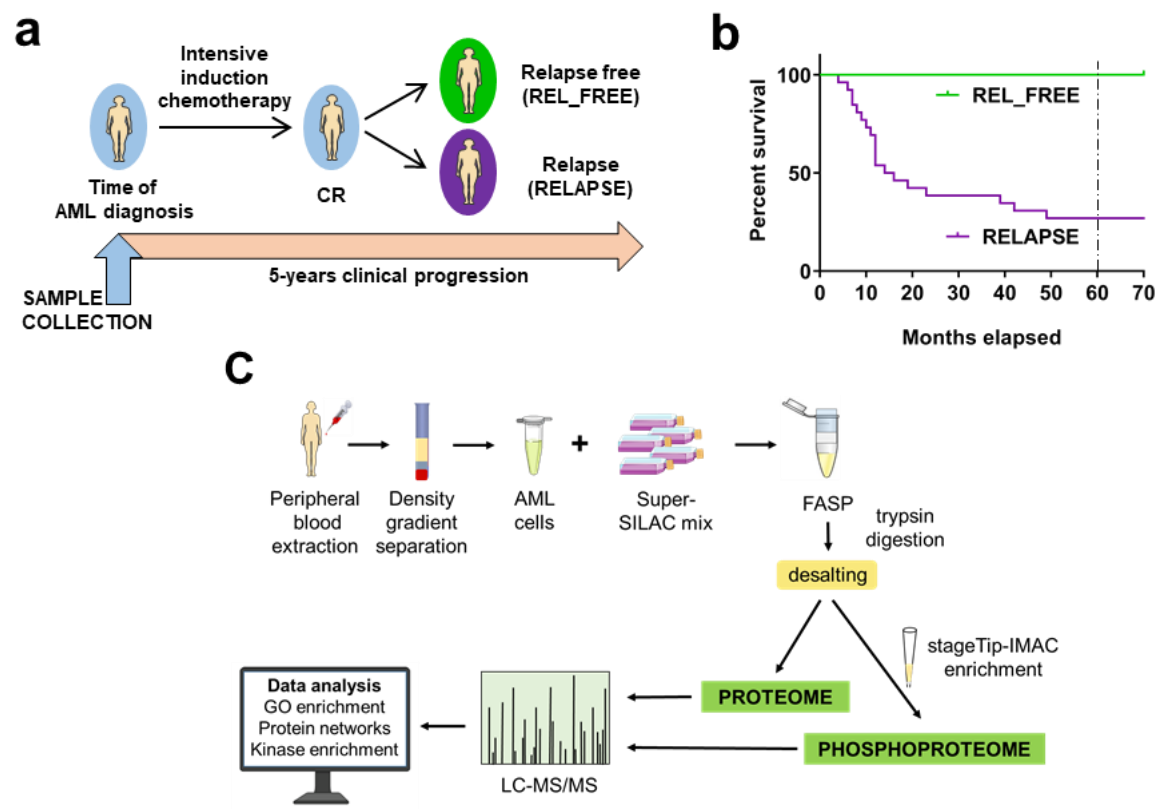

Figure 1. Overview of the RELAPSE and REL_FREE AML patient cohort and the workflows for the proteome and phosphoproteome analysis of acute myeloid leukemia (AML) patient cells. (a) The study included AML cell samples from 26 RELAPSE and 15 REL_FREE patients collected at the time of first diagnosis. All patients received intensive induction chemotherapy, consolidation therapy and achieved complete remission (CR), as described in Materials and Methods. Patients were classified after an observation time of at least five years from the initial therapy. (b) Survival plot for the patients included in each group. Dashed line indicates the five-years observation time. (c) AML sample preparation steps for proteome and phosphoproteome analysis include blood extraction, blast isolation, cell lysis, addition of super-SILAC (Stable Isotope Labeling with Amino Acids in Cell Culture) mix, filter-aided sample preparation (FASP)-based protein digestion and additional immobilized metal affinity chromatography (IMAC) enrichment of phosphopeptides. After liquid chromatography tandem mass spectrometry (LC-MS/MS) acquisition, our proteomic workflow ends with bio-computation and validation analyses. 
Table 1. Characteristics of the 41 AML patients used in the study at the first time of diagnosis.

\begin{tabular}{ccc}
\hline Characteristic & REL_FREE & RELAPSE \\
\hline Age average (range) in years & $49.5(36-65)$ & $50.5(18-68)$ \\
\hline Number of patients & 15 & 26 \\
\hline FAB classification & & \\
\hline M0-M1 & 1 & 11 \\
M2 & 0 & 2 \\
M4-M5 & 14 & 12 \\
uncertain & 0 & \\
\hline FLT3 & & 14 \\
WT & 14 & 4 \\
ITD & 1 & \\
ND & 0 & 76 \\
NPM1 & & 3 \\
\hline WT & 6 & \\
Ins & 1 & \\
\hline ND & & \\
\hline
\end{tabular}

FAB: French-American-British; WT: wild type; ITD: internal tandem duplication; Ins: a 4 bp-insertion/duplication; $N D$ indicates not determined

Patients with and without relapse showed expected differences in the frequencies of favorable NPM1 mutations (increased in REL_FREE patients) and adverse FLT3-ITD (increased in RELAPSE patients) [8]. Furthermore, REL_FREE patients also showed a high frequency of monocytic differentiation by their leukemic cells (i.e., FAB M4/M5), that was significantly different from the RELAPSE patients (Fischer's exact test, $p=0.003$ ). This is mainly due to the expected and significant association between NPM1 mutations and morphological signs of differentiation (i.e., low frequency of FAB M0/M1 and high frequency especially of M4/M5; Fischer's exact test, $p=0.023$ ) but one inv(16) patient with expected M4 morphology also contributed. Previous studies have also described an association between NPM1 mutations and morphological signs of differentiation and expression of the CD33 differentiation marker, as well as an inverse correlation with expression of the CD34 stem cell marker [34,35]. Thus, all observations described above are expected and can be explained by previously described characteristics of AML patient subsets in large AML studies.

\subsection{The Protein Abundances of rRNA Processing Proteins and V-ATPase Subunits Differ Between RELAPSE and REL_FREE Patients}

We compared the proteome profiles of AML cells derived from 26 RELAPSE and 15 REL_FREE patients at the time of diagnosis, obtained according to our filter-aided sample preparation (FASP)-based workflow (Figure 1c). We quantified 6781 proteins, of which 5309 had a quantitative value in at least five patients in each group. The t-test based statistical analysis resulted in 351 differentially expressed proteins; 210 proteins were upregulated and 141 were downregulated in the RELAPSE relative to REL_FREE group (Supplementary file 1). The proteome of patient-derived cell lysates was also processed and quantified using label-free quantification (LFQ), for validating the super-SILAC based proteome quantitation (Supplementary data, Figure S1, Figure S2, Figure S3 and Supplementary file 1). The RELAPSE vs. REL_FREE fold changes (FCs) of the 4041 proteins quantified in both experiments had good correlation (Pearson $R=0.72$; Figure $S 2$ ).

Hierarchical clustering of the 351 differential proteins grouped the patients into two main clusters (Figure 2a), which corresponded to the RELAPSE and REL_FREE samples, although a distinct separation was not obtained. Gene ontology (GO) enrichment analysis showed that ATPase activity (coupled to transmembrane movement of ions, rotational mechanism), proton-exporting ATPase activity, phagosome acidification and iron ion transport (Figure 2b) were more abundant processes in the REL_FREE patients. These terms include proteins of the vacuolar $(\mathrm{V})-\mathrm{H}^{+}$-ATPase, an 
ATP-dependent proton pump in cellular membranes, such as lysosomes and endosomes [36]. The proteins enriched in this group were primarily located in the cytosol or extracellular organelles, such as vesicles. In contrast, proteins involved in ribosomal processes, such as rRNA metabolic process, ncRNA processing and ribonucleoprotein complex biogenesis were clearly higher in the RELAPSE patients, where $46 \%$ of the increased proteins were annotated to the nucleolus in the cellular compartment analysis (Figure $2 b$ ).

Moreover, a protein-protein interaction (PPI) network of the differentially expressed proteins (Figure 2c) confirmed the increased abundance of proteins involved in rRNA processing and ribosome biogenesis in relapsed patients (cluster 1; 69 proteins). RRP1B $(p<0.0002$, FC 1.09) and AATF $(p<0.0002$, FC 0.91) were the most significant proteins in this cluster. AATF (also known as CHE1) participates in several cellular pathways, such as $40 \mathrm{~S}$ ribosomal subunit synthesis in complex with NGDN ( $p=0.0014$, FC 0.95) and NOL10 ( $p=0.0007$, FC 0.85) [37], and high AATF expression has been linked to variants of leukemia $[38,39]$. Other proteins in this cluster were CEBPZ, a transcription factor in the CEBP family, several WD repeat-containing proteins (e.g., WDR3, WDR18, WDR36), probable ATP-dependent RNA helicases (e.g., DDX18, DDX27, DDX56) and members of the C/D box small nucleolar ribonucleoprotein (snoRNP) complex (NOP56 and NOP58), which guides 2'O methylation of the rRNA. Proteins involved in neutrophil degranulation dominated cluster 2 and nine subunits belonging to the V-ATPase complex were identified in cluster 3 (Figure 2c), all with higher abundance in the REL_FREE patients. Regulated V-ATPase subunits (cluster 3) and proteins participating in rRNA processing and ribosomal biogenesis (cluster 1) are detailed in Supplementary file 2. Cluster 4 and 5 contained proteins involved in chromatin remodeling and RNA polymerase I subunits, respectively, which were upregulated in the RELAPSE patients.

The gene set enrichment analysis (GSEA) against the Hallmark gene set collection, conducted to identify classes of genes overrepresented in the complete dataset, resulted in HALLMARK_MYC_TARGETS_V2 (systematic name: M5928), as the only significant gene set (false discovery rate, FDR, $q$-value $=0.046$ ) (Figure S4). This gene set was upregulated in the RELAPSE group and consisted of 58 genes [40]. A total of 15 out of the 30 proteins who contributed most to the gene set enrichment results (i.e. the leading edge subset) were found in cluster 1 in Figure 2c.

Using the data on time from diagnosis to relapse (Table S1), we further classified the RELAPSE patients into two groups: 14 EARLY RELAPSE and 12 LATE RELAPSE patients with first relapse occurring before and at/after 12 months from diagnosis, respectively, in alignment with reported remission duration [41,42]. We found 236 and 295 differentially expressed proteins in the EARLY RELAPSE vs. REL_FREE and in the LATE RELAPSE vs. REL_FREE comparisons, respectively. One hundred and twelve regulated proteins from each set overlapped and some of these belonged to the ribosome biogenesis RNA processing, the DNA-directed RNA polymerase and V-ATPase clusters that we identified when we analyzed all the RELAPSE patients together (Figure S5, Figure 2c). Thus, although the EARLY and LATE RELAPSE proteomes might show some features related to the different relapse timings, regulation of relevant protein networks were observed in all relapsed patients.

\subsection{Differential CDK, CSK2 and PRKCA/D Kinase Activities between RELAPSE and REL_FREE Patients}

We constructed a dataset comprising 12,309 identified and quantified class I protein phosphorylation sites from 3003 proteins of 26 RELAPSE and 15 REL_FREE patients. Serine phosphorylation made up the majority of the identified phosphosites $(89.7 \%)$ while phosphorylation on threonine and tyrosine $(10.0 \%$ and $0.3 \%$, respectively) comprised the rest. We identified 274 differentially regulated phosphorylated sites based on a statistical analysis of 5634 phosphosites, which were quantified in at least five patients in each group (Supplementary file 3).

Hierarchical clustering using these 274 phosphosites divided the phosphoproteome of RELAPSE and REL_FREE patients (Figure 3a). Two clusters, one containing 138 phosphosites and another with 136 phosphosites, were upregulated and downregulated in the RELAPSE, relative to REL_FREE patients, respectively (Supplementary file 3). 


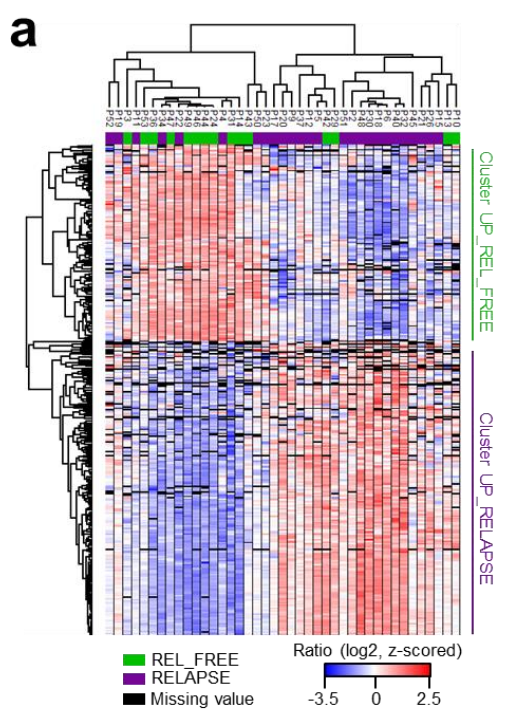

b
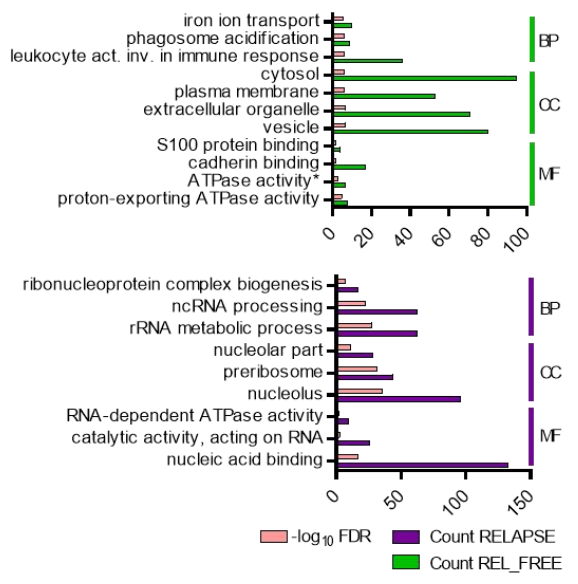

C
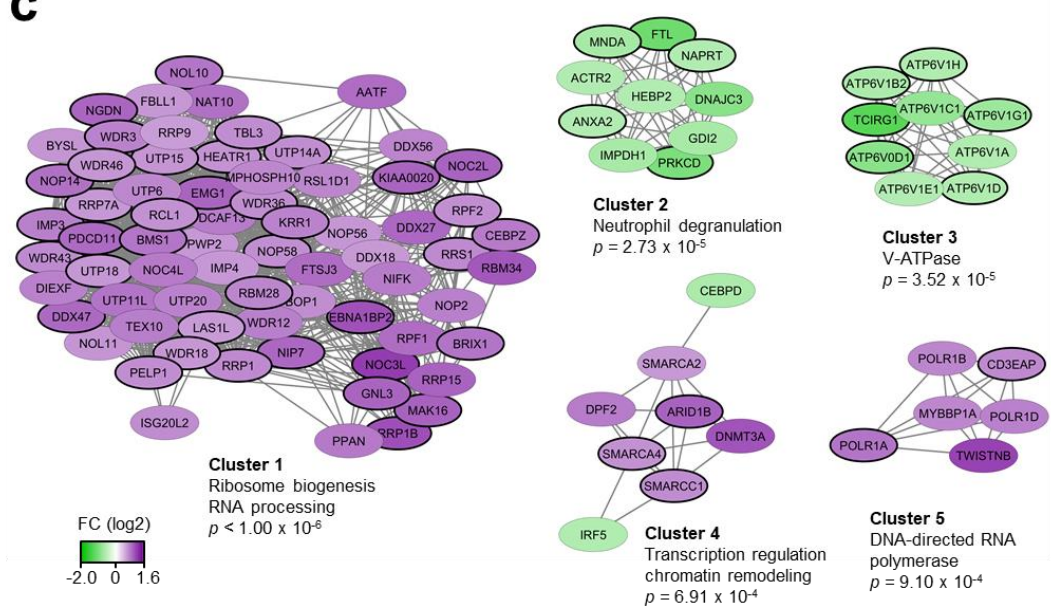

Figure 2. The global AML cell proteome shows increased abundance of rRNA processing proteins and decreased abundance of V-ATPase subunits for patients who relapse. (a) Hierarchical clustering of the patients (P1-P53), based on protein expression (SILAC $\log _{2}$ ratio) of the 351 proteins with significantly different regulation in AML cells from REL_FREE (green) and RELAPSE (purple) patients. Two vertical main clusters were observed, one dominated by proteins with higher abundance in mostly REL_FREE patients (Cluster UP_REL_FREE) and the other by proteins with higher abundance in RELAPSE patients (Cluster UP_RELAPSE). (b) Gene ontology (GO) analyses of the two protein clusters identified in Figure 2a were performed, to reveal enriched biological processes (BP; see the right side of the figure), cellular compartments (CC) and molecular functions (MF) in the two protein clusters. The upper part of the figure corresponds to the upper REL_FREE cluster identified in Figure 2a, whereas the lower part of the figure corresponds to the lower RELAPSE cluster. The various enriched GO terms are listed in the left part of the figure. The number of proteins associated to a specific GO term (count) and the corresponding $-\log _{10}$ false discovery rate (FDR) of these top significant GO terms are shown on the x-axis. *The complete name of the GO term referred to as ATPase activity in the figure is "ATPase activity, coupled to transmembrane movement of ions, rotational mechanism". (c) Protein-protein interactions (PPI) networks of the 351 proteins from the STRING database, visualized and analyzed with Cytoscape and ClusterONE, respectively. The five clusters with highest significance of cohesiveness are shown with $p$ values of a one-sided Mann-Whitney $\mathrm{U}$ test. The protein nodes are colored according to their RELAPSE/REL_FREE $\log _{2}$ fold change (FC), i.e., purple indicates increased abundance in the RELAPSE group and green increased abundance in the REL_FREE group. Protein nodes with black border represent significantly regulated proteins found in both the SILAC and label-free datasets. 

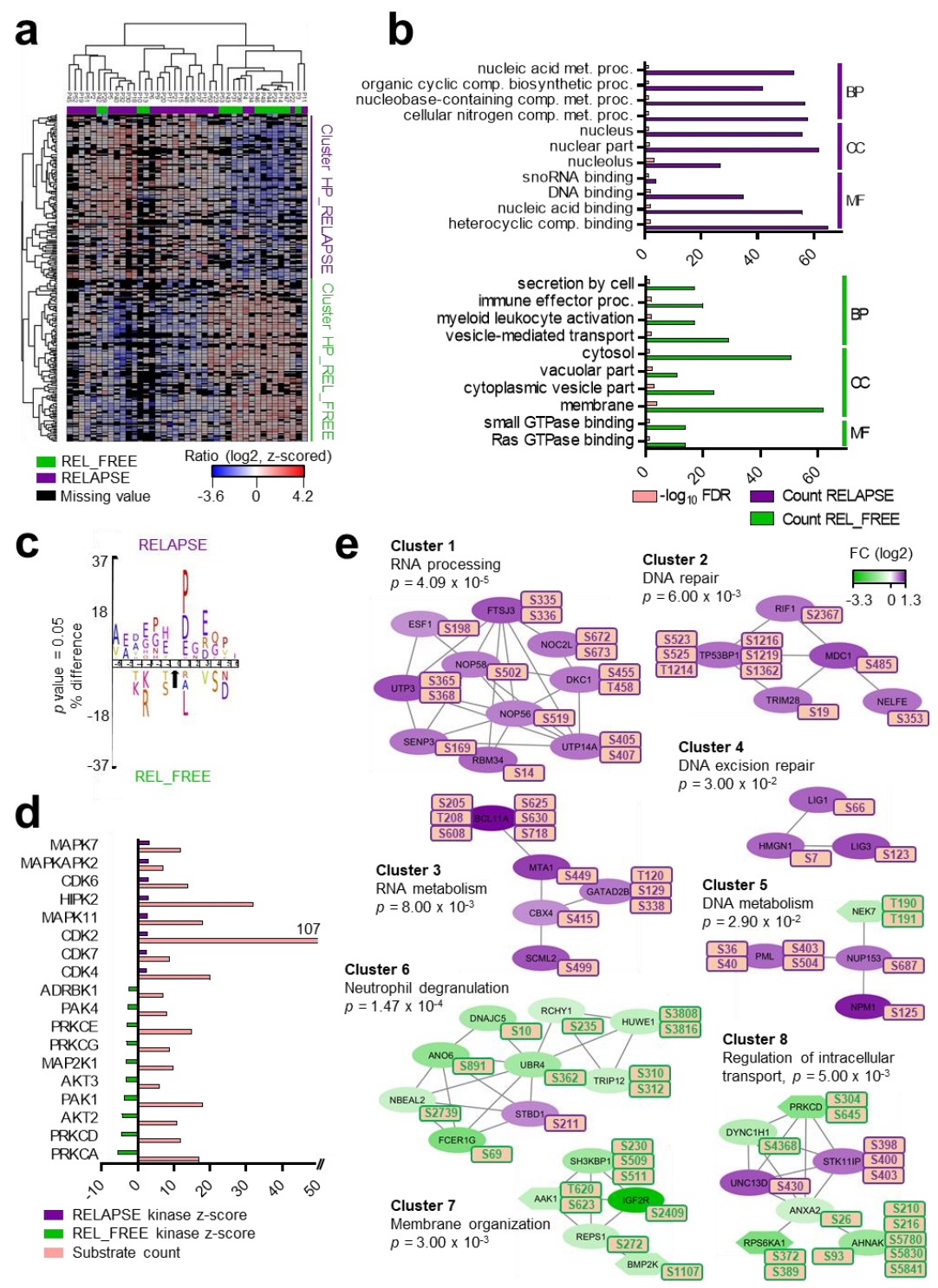

Figure 3. The AML RELAPSE phosphoproteome is enriched in cyclin-dependent kinase (CDK) substrates and RNA processing casein kinase 2 (CSK2) targets. (a) Hierarchical clustering of 274 differentially regulated phosphorylation sites revealed two clusters: HP (High Phosphorylation)_RELAPSE (in purple) and HP_REL_FREE (in green). The SILAC $\log _{2}$ ratio scale and color code is also shown. (b) GO analyses of the two phosphoprotein clusters identified in Figure 3a were performed to reveal enriched $\mathrm{BP}$, indicated to the right in the figure, $\mathrm{CC}$ and MF. The GO terms are listed in the left part of the figure; the upper part of the figure corresponds to the upper RELAPSE cluster identified in Figure 3a whereas the lower part of the figure corresponds to the lower REL_FREE cluster. The x-axis indicates the number of phosphoproteins/FDR. (c) Sequence motif analysis of the \pm six amino acids, flanking the differentially regulated phosphorylation sites for either cluster. (d) Kinase-substrate enrichment analysis (KSEA) of differentially regulated and unregulated phosphorylation sites. The kinase z-score ( $\mathrm{X}$ axis) is the normalized score for each kinase ( $\mathrm{Y}$ axis), weighted by the number of identified substrates. (e) Networks of PPI based on STRING database and visualized in Cytoscape after ClusterONE analysis. Significance of networks of high cohesiveness is shown with the $p$ value of a one-sided Mann-Whitney $\mathrm{U}$ test. The differentially regulated phosphorylation site(s) is shown next to each protein. FC of phosphorylation are color-coded; purple-colored proteins showed a higher phosphorylation in the RELAPSE group and green-colored proteins showed a higher phosphorylation in the REL_FREE group. Kinases are specifically distinguished using hexagon shapes. 
Cellular component GO analysis revealed an enrichment of upregulated nuclear phosphoproteins for RELAPSE patients, whereas cytoplasm, cytosol, membranes and vacuolar structures were enriched in the REL_FREE group (Figure 3b). Immune effector process, myeloid leukocyte activation and GTPase binding were the biological processes and molecular functional GO terms enriched in this group.

To identify protein kinases differentially activated in the two groups, we performed a phosphorylation site motif analysis (IceLogo) [43]. We found a strong bias towards acidic amino acids such as glutamic acid (E), in close proximity to the differentially phosphorylated sites in the RELAPSE group when compared to the unregulated phosphosites (Figure S6a), suggesting a higher casein kinase 2 (CSK2) activity in this group. Using differentially phosphorylated sites in the REL_FREE group, the analysis identified a basophilic KXpS/pT motif, suggesting a moderate activation of protein kinase C types, PRKCA and PRKCD (Figure S6b). Moreover, proline-directed motifs for phosphorylation by mitogen-activated protein kinases (MAPKs) and cyclin-dependent kinases (CDKs) were underrepresented in the REL_FREE group. When we directly compared the sequences surrounding the differentially regulated phosphorylation sites in the RELAPSE and REL_FREE groups, higher CSK2, MAPK and CDK activation was observed in the RELAPSE, and higher PRKCA/D in the REL_FREE group, confirming the previous motif analysis (Figure 3c, Supplementary file 4). Furthermore, the kinase-substrate enrichment analysis (KSEA) [44,45], which is based on phosphorylation FCs to estimate kinase's activity, confirmed the higher activity of several MAPKs and CDKs in the RELAPSE group and the higher activity of PRKCA, PRKCD and AKT serine/threonine kinases in the REL_FREE group (Figure 3d). We found nine phosphosites on six different protein kinases in the data set of 274 differentially regulated phosphorylation sites. Seven of the nine phosphosites (including those on PRKCD, PAK2, MAP3K3, BMP2K and NEK7 kinases) were found to be upregulated in the REL_FREE group relative to the RELAPSE group. In particular, sites on the kinase domain activation loop of NEK7 (T190 and T191) were more abundant in the REL_FREE group. Conversely, phosphorylation of the receptor-type tyrosine-protein kinase FLT3 on S759 and S762 was higher in the RELAPSE group relative to the REL_FREE group.

Several PPI networks of significant cohesiveness were found after a ClusterONE analysis based on STRING interactions of differentially phosphorylated proteins (Figure 3e). Even if stringent criteria in STRING was used, we should point out that false positives could occur in the networks. The most significant network (cluster 1) consisted of ten phosphoproteins with higher phosphorylation in RELAPSE patients, most of them being RNA binding proteins. A sequence logo analysis [46] of the amino acids surrounding the 15 phosphosites (corresponding to the ten proteins) suggested a higher activation of CSK2 in this cluster (Figure S7a). Other significant clusters included DNA binding proteins (clusters 2 and 4) and proteins involved in nucleic acid metabolism (clusters 3 and 5). A sequence logo analysis of the amino acids surrounding the phosphosites in clusters 2, 3 and 5 showed an enrichment of MAPK substrates (Figure S7b-d), although NPM1 S125 in cluster 5 is phosphorylated by CSK2 [47], and amino acid sequences around HMGN1, LIG1 and LIG3 phosphosites in cluster 4 suggested the involvement of other kinases, such as CSK2 and CDKs [48,49]. Finally, transcription factor BCL11A, which functions as a myeloid proto-oncogene, and DNA repair protein TP53BP1 showed higher phosphorylation on multiple sites in the RELAPSE group relative to the REL_FREE group. PPI networks that showed higher phosphorylation in the REL_FREE group were involved in neutrophil degranulation (cluster 6), membrane organization (cluster 7) and intracellular transport (cluster 8). Sequence logo analysis of the phosphosite motifs in these clusters suggested a higher activation of PRKCD/A kinases (Figure S7e-g).

To further elucidate the molecular source of AML relapse in these patients, we utilized the proteome and phosphoproteome data in order to determine transcription factors responsible for driving relapse. Specifically, proteins involved in DNA transcription that were regulated at both the proteome or phosphoproteome level in the RELAPSE group were compared to ChIP-seq data from the K562 cell line (stored in the ENCODE database), in order to find the potential binding sites of transcription factors (Table S3). We identified six transcription factors (AFF1, CEBPZ, ETV6, IKZF1, 
PML and TRIM28) that showed the predicted regulation of proteins involved in DNA and RNA binding proteins, damaged DNA binding proteins, ribosome and carcinogenesis pathways based on GO molecular function terms and KEGG pathways analysis (Figure S8).

To explain the generally increased phosphosite regulation in the RELAPSE group, we compared the protein expression to the 274 differentially regulated phosphosites (corresponding to 169 phosphoproteins). We found that 107 (63\%) phosphoproteins were not significantly changed at the protein level (Supplementary file 3). Among them, we noticed all the phosphoproteins of the DNA repair network (cluster 2) in Figure 3e (Figure S9). In contrast, we spotted 34 proteins significantly regulated at both protein and phosphosite level, including six phosphoproteins of the RNA processing network (cluster 1) in Figure 3e (Table S4 and Figure S10). For the majority of these phosphosites (including FLT3 and PML), the phosphorylation levels correlated closely with their protein expression levels. Taken together, while RELAPSE AML cells had higher expression of several phosphorylation-prone proteins, nearly $50 \%$ of the differentially regulated phosphorylation sites could not be explained by protein expression changes, suggesting increased kinase-specific phosphorylation.

In order to study the phosphorylation landscape of early and late relapsed patients separately, we reanalyzed the phosphoproteome dataset, classifying the RELAPSE into EARLY RELAPSE or LATE RELAPSE patients, as we did with the proteome dataset. We found 211 and 164 differentially regulated phosphorylated sites in the EARLY RELAPSE vs. REL_FREE and in the LATE RELAPSE vs. REL_FREE comparisons, respectively. Only 34 differentially regulated phosphosites were found in both subcohorts (Figure S11a). A PPI network analysis found components of some of the phosphoprotein clusters with higher phosphorylation in RELAPSE (clusters 1,2 and 3) and with higher phosphorylation in REL_FREE group (clusters 6 and 8), identified when we analyzed all the RELAPSE patients together (Figure 3e) in the EARLY RELAPSE vs. REL_FREE dataset, whereas a new mixed cluster composed of RNA metabolism phosphoproteins, transcriptional regulators and SUMOylate target proteins was found in the LATE RELAPSE vs. REL_FREE dataset (Figure S11b,c). These results showed the differentiation of phosphorylated signatures in patients with early and late relapse at diagnosis.

\subsection{V-ATPase, CSK2, CDK2/7/9 and CDK4/6 Inhibitors Affect the Proliferation of AML Cells}

To explore the potential of V-ATPase inhibition in AML, we tested the effect of the V-ATPase inhibitor bafilomycin A1 (BafA1) in pilot dose-response experiments and observing the growth of AML cells from four REL_FREE and seven RELAPSE patients, with high or low abundance of V-ATPase subunits, respectively (Figure S12a). We found non-significant differences in cell viability for RELAPSE and REL_FREE groups when treated at $10 \mathrm{nM}$ BafA1 and in cell proliferation when treated with 1, 5 and $10 \mathrm{nM}$ BafA1 (Figure 4a,b), although the inhibitor had a smaller effect on proliferation of REL_FREE cells when used at $10 \mathrm{nM}$. The proliferation was significantly higher in the untreated control RELAPSE cells compared to REL_FREE cells (Figure S12b). However, BafA1 at $10 \mathrm{nM}$ decreased significantly $(p=0.018)$ the proliferation of cells for most of RELAPSE patients, whereas the proliferation of cells for three out of four REL_FREE patients was not significantly altered (Figure 4c,d).

In order to further investigate whether the activity of the predicted RELAPSE-activated kinases was essential for cell survival and proliferation, we tested the proliferation in available AML cells from ten RELAPSE and nine REL_FREE patients in the presence of inhibitors of CSK2, CDK2/7/9, CDK4/6 and ERK1/2, alone or in combination (Table S5). As shown in Figure 4e, the CSK2 inhibitor CX-4945 at $5000 \mathrm{nM}$ seemed to be slightly more potent inhibitor of REL_FREE cells compared to RELAPSE cells. Similarly, the combination of CDK4/6 inhibitor abemaciclib $(50 \mathrm{nM})$ with CDK2/7/9 and CSK2 inhibitors (SNS-032 $50 \mathrm{nM}$; CX-4945 $1500 \mathrm{nM}$ ) decreased cell proliferation significantly only for the REL_FREE cells $(p=0.008)$ (Figure 4f). The RELAPSE cells showed significant antiproliferative effect only when exposed to a high concentration (15000 nM) of CX-4945 inhibitor. 
a

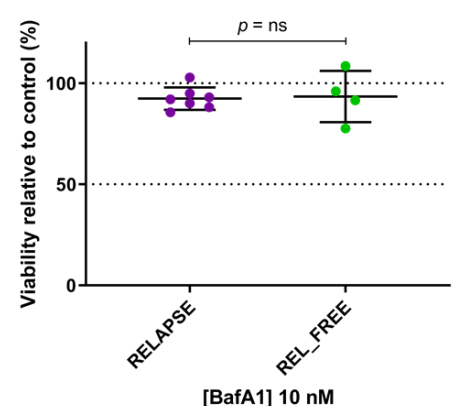

C
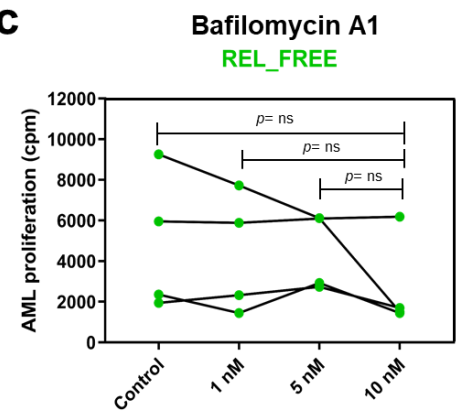

e

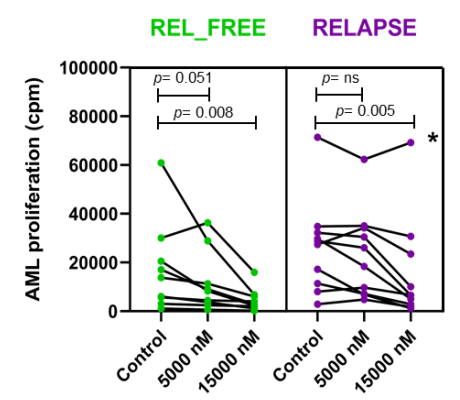

\section{b}

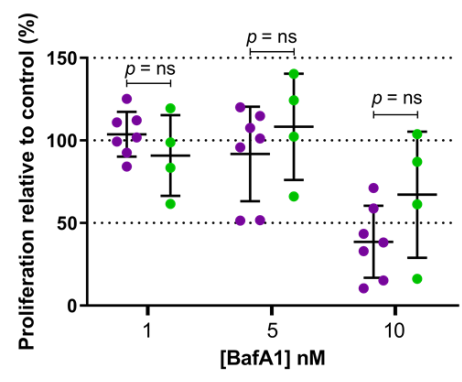

d

Bafilomycin A1 RELAPSE

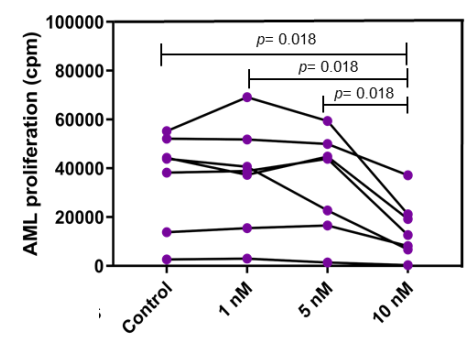

f

i) Abemaciclib + SNS-032

ii) Abemaciclib + CX-4945 REL_FREE RELAPSE

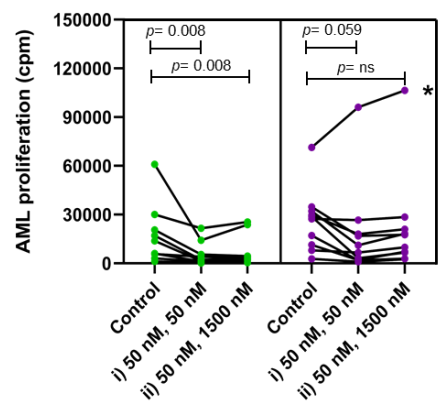

Figure 4. The effect of inhibitors of V-ATPases, casein kinase 2 (CSK2) or cyclin-dependent kinases (CDKs) on AML cell proliferation. AML patient cells were treated for six days with the indicated inhibitors. The thymidine incorporation-based proliferation measurements are presented as dots (purple for RELAPSE and green for REL_FREE) in patient groups or in individual patient curves. Significance of inhibitor treatment between patient groups and of inhibitor treatment vs. untreated control was found using the Mann-Whitney $U$ test and the Wilcoxon matched-pair signed rank test, respectively. Non-significant results are indicated with " $p=n s$ ". (a) Viability of cells relative to untreated control for RELAPSE and REL_FREE groups, when treated with $10 \mathrm{nM}$ of V-ATPase inhibitor Bafilomycin A1 (BafA1). (b) Differences of cell proliferation relative to control for RELAPSE and REL_FREE groups when treated at 1, 5 and $10 \mathrm{nM}$ BafA1. (c,d) Cells from four REL_FREE and seven RELAPSE patients treated with BafA1. The RELAPSE, but not the REL-FREE, patients had decreased proliferation (measured after 6-7 days of culture) when treated with $10 \mathrm{nM}$ BafA1 inhibitor compared to control, 1 and $5 \mathrm{nM}$. Non-significant change was observed between control and $1 \mathrm{nM}$ or $5 \mathrm{nM}$ BafA1 inhibitor for either groups. $(\mathbf{e}, \mathbf{f})$ Cells from nine REL_FREE and ten RELAPSE patients (five and four of them were external to the patient cohort, respectively) were treated with CSK2, CDK2/7/9 and CDK4/6 kinase inhibitors in cell proliferation assays, alone or in combination. The CSK2 inhibitor CX-4945 was given at 0 (i.e., control), 5000 and $15000 \mathrm{nM}$ alone. The CDK4/6 inhibitor Abemaciclib (50 nM) was given in combination with i) the CDK2/7/9 inhibitor SNS-032 $(50 \mathrm{nM})$ and ii) CX-4945 (1500 nM). The same RELAPSE patient with high cell proliferation is represented with an asterisk $\left({ }^{*}\right)$. 
These cell proliferation studies with the kinase inhibitors showed that the RELAPSE group included an exceptional patient (marked with * in Figure 4e,f). When leaving this patient out from the statistical comparison of CX-4945 monotherapy, the same differences remained statistically significant as when all patients were included (see Figure 4e right part). However, when analyzing the effects of abemaciclib combinations without this exceptional RELAPSE patient, we obtained a $p$ value of 0.008 for the inhibitor-free control vs. abemaciclib + SNS-032, whereas this $p$ value was not significant 0.059 if all RELAPSE patients were included (see Figure $4 \mathrm{f}$ right part). Furthermore, a $p$ value of 0.038 was seen if this patient was excluded from the comparison of inhibitor-free control vs. abemaciclib + CX-4945 (not significant when all RELAPSE patients were included, see Figure 4f right part). AML is a heterogeneous disease and the detection of single exceptional patients is, in our opinion, expected. However, even when leaving out this exceptional RELAPSE patient, the antiproliferative effects were generally stronger for REL_FREE than for RELAPSE patients when testing abemaciclib + SNS-032 (median proliferation in percent of the inhibitor-free control cultures being $36 \%$ with range $11-97 \%$ for REL_FREE vs. median $41 \%$ with range 10-72\% for RELAPSE patients) and abemaciclib + CX-4945 (median $41 \%$ with range 19-85\% for REL_FREE vs. median $63 \%$ with range $17-104 \%$ for RELAPSE patients).

Western blot analyses using lysates from three RELAPSE and three REL_FREE patient cells incubated with media (control) or CDK2/7/9 or ERK1/2 inhibitors showed both higher CDK2 expression and higher phosphorylation on T160 in the RELAPSE group, although differences between groups were only significant for the phosphorylated protein in the control samples and after treatment with SNS032 inhibitor (Figure S13b). SNS032, a compound that targets the kinase catalytic ATP-binding pocket [50], did not affect CDK2 T160 phosphorylation in any group, although this might be due to the short incubation time (15 min) used in the experiment [51,52]. The phosphorylation of ERK1/2 was low and similar in the two patient groups. SCH772984, an ATP-competitive compound of ERK1/2 [53], decreased kinase activity similarly in the RELAPSE and REL_FREE samples. These findings correlate with the phosphoproteome analyses, showing a higher relative abundance of phosphorylated CDK2 substrates, but not of ERK1/2 substrates, in the RELAPSE group.

\section{Discussion}

Chemoresistant disease (i.e. primary resistance or chemoresistant relapse) is a major cause of death in AML [8]. In this study, we compared the proteomic profiles at the time of first diagnosis for patients with later relapse and patients without leukemia relapse, after an observation time of at least five years from the initial intensive and potentially curative induction and consolidation therapy.

Many of the statistically significant proteomic differences between patients with and without leukemia relapse were relatively small, and for this reason we did not only focus on statistically significant differences of single proteins, but also on proteomic/phosphoproteomic profiles and the similarities in biological functions for groups of differing proteins. However, we want to emphasize that the biological significance of the observed proteomic differences can only be proven by additional empirical testing. Furthermore, our present study should be regarded as a population-based study; treatment-related mortality or morbidity do not influence our results because we excluded those patients who died from or could not complete the planned intensive treatment due to severe treatment-related toxicity.

A detailed methodological discussion is therefore necessary to ensure correct and careful interpretation of our results. Our study included patients with a relative high percentage of AML blasts among circulating leukocytes. This selection was necessary to prepare highly enriched AML cell populations by a simple and standardized gradient separation alone. This strategy was chosen because more extensive cell separation procedures can alter the molecular profiles of AML cells. The possible consequences of these alterations have been discussed in detail previously $[54,55]$. Firstly, we previously compared the characteristics of patients selected according to these criteria (corresponding to approximately half of the consecutive patients), with the other patients without 
high peripheral blood blast counts during a defined time period, and we could not detect any significant differences with regard to karyotype or FLT3 mutations [56]. Secondly, in a previous study including 71 patients selected according to these criteria, we observed an expected frequency of various submicroscopic mutations in 54 genes frequently mutated in AML [12-14,34], that is also recognized in our present patient cohort (Table S1). Finally, our two patient subsets with and without relapse after completed intensive therapy are defined by very simple criteria, and the observation time used to define relapse-free patients is long. Thus, our population-based patient cohort does not differ from other larger AML patient cohorts, with regard to karyotypes and submicroscopic mutational frequencies, and the two patient subsets are defined by simple criteria based on in vivo chemosensitivity. Moreover, the association between proteomic patterns and clinical indicators such as genetic mutations and cytogenetics has been recently shown to be limited in AML suggesting proteomic-defined signatures as independent prognostic factors [57]. Therefore, further stratification analysis of the AML samples based on their FAB classification or genetic mutations might not provide additional prognostic information.

The peripheral blood blast level may have an adverse prognosic impact in AML patients receiving intensive chemotherapy, although this impact is very weak compared with karyotype and genetic abnormalities [58]. In a previous HOVON/Sakk clinical study, leukocytosis exceeding $2 \times 10^{9} / \mathrm{L}$ was regarded as a risk factor for patients with $\mathrm{t}(8 ; 21)$ [59], but this could not be confirmed in a recent separate study [60]. Furthermore, the most recent ELN guidelines do not recommend the use of peripheral blood blast counts in the prognostic evaluation of AML patients either [8]. Despite the similarities in genetic abnormalities, it can therefore be argued that we studied a patient cohort with increased chemoresistance compared with AML in general, and not only for patients with high blood blast counts. Recent studies also suggest that the leukocyte count may have a prognostic impact, but only in the small subset of patients with leukocyte counts exceeding 50 or even $100 \times 10^{9} / \mathrm{L}[59,61,62]$. Only six out of our 41 patients had leukocyte counts exceeding $100 \times 10^{9} / \mathrm{L}$ and most patients had counts below $50 \times 10^{9} / \mathrm{L}$. Thus, we cannot exclude that the observations in our present in vivo chemotherapy study are representative only for patients with circulating AML blasts, but our selection of patients with a high percentage of circulating blasts probably represents only a minor difference from AML in general with regard to in vivo chemosensitivity.

Our proteomic and phosphoproteomic study was based on peripheral blood and not bone marrow cells, even though AML is by definition a bone marrow disease [2], but for several reasons we regard peripheral blood cells to be relevant. First, flow cytometric studies of molecular profiles have only detected limited quantitative but not qualitative differences between peripheral blood and bone marrow cells from the same patients [63]. Recently, the reverse phase protein array (RPPA)-based proteomic profiling of blood-derived AML samples were found to be similar to that of marrow-derived samples [57]. Second, the fundamental AML associated genetic abnormalities are also detected in the peripheral blood cells. Third, peripheral blood cells also have a hierarchical organization and include cells capable of long-term in vitro proliferation (i.e., leukemic stem cells) [64] and functional comparisons of blood and bone marrow AML cells from the same patient also suggest that they show relatively small differences [65]. Finally, the definition used for most patients for the diagnosis of AML is the detection of at least $20 \%$ blasts in the bone marrow [2]. More extensive cell separation procedures would therefore be required to achieve highly enriched AML bone marrow cell populations and such separation procedures may then alter the cell characteristics [55].

The final methodological question is the use of cryopreserved total AML cell populations for our studies. Even though cryopreservation and thawing would be expected to influence proteomic and phosphoproteomic profiles in AML cells, our previous methodological studies with comparison of paired (i.e., both samples derived from the same patient) cryopreserved and fresh AML cell samples suggested that this influence is limited [31]. All samples in our study were cryopreserved by using the same standardized technique and without any difference in storage time between our two patient subsets. Furthermore, both our present in vivo chemotherapy study and several previous 
patient studies have demonstrated that the biological characteristics of the total hierarchical AML cell population reflect the risk of relapse (i.e., the chemosensitivity), both with regard to genetic abnormalities as well as constitutive in vitro cytokine release, global and stem cell gene expression profiles, epigenetic characteristics and intracellular pathway activation [12-14,66-72]. Thus, even though leukemic stem cells are regarded as responsible for AML relapse [73], biological characteristics associated with relapse risk are also reflected in the total AML cell population.

Despite the patient heterogeneity, significant overall differences were observed at the proteome and phosphoproteome level for several biological processes between AML cells from RELAPSE and REL_FREE patients, harvested at the time of diagnosis. In particular, proteins involved in ribosome biogenesis and rRNA processing/regulation were more abundant and more strongly phosphorylated in RELAPSE patient cells. This finding of rRNA processing upregulation was supported by the ChIP-seq data analysis from the K562 cell line, where we found several transcriptions factors promoting the transcription of genes for RNA polymerase (CEBPZ) and ribosome/ribosomal biogenesis (PML, AFF1, ETV6 and TRIM28). Deregulated RNA binding proteins and ribosome biogenesis can be drivers of cancer pathogenesis [74,75]. Furthermore, the GSEA analysis revealed enrichment of MYC targets in RELAPSE patients. MYC is frequently overexpressed in AML as well as other leukemic malignancies, and seems to be a crucial transcriptional factor during hematopoiesis [76,77]. MYC is also a regulator of ribosome biogenesis [78], activates RNA pol I for rDNA transcription [79] and induces snoRNA expression [80]. As MYC targets are enriched during relapse, our findings suggest that MYC, together with proteins involved in rRNA processing and ribosome biogenesis, are prognostic biomarkers for relapse and potential therapeutic targets in AML. Several drugs targeting rRNA synthesis, transcription or processing in hematological cancers have already been described [81,82].

We observed an increased abundance of V-ATPase subunits in REL_FREE patients. The V-ATPase complex can modulate several intracellular signaling pathways with importance in AML (such as PI3K-mTOR [83,84], NOTCH1 [85] and WNT [86]) by controlling acidification of intracellular compartments. V-ATPase is also important for autophagy [87]. Two previous studies have described an association between low expression at the mRNA level of single autophagic regulators and an adverse prognosis. First, BECN1 is important for the initiation and advance of autophagy, and reduced $B E C N 1$ mRNA levels were associated with an adverse prognosis, FLT3-ITD, monosomal karyotype and high age [88]. Second, decreased BECN1 mRNA expression is also associated with an adverse prognosis [89]. Thus, our present studies suggest that the expression profile of mediators involved in autophagy is associated with prognosis in human AML, and to the best of our knowledge our present study is the first to describe this for several mediators and at the protein level.

When testing the effect of V-ATPase inhibitor on AML cells, we observed that the RELAPSE derived cells with initially low abundance of V-ATPase subunits responded better to BafA1 V-ATPase inhibitor, thus, a potential relationship between low initial V-ATPase subunit abundance and chemoresistance needs further evaluation. V-ATPase is regarded as a potential therapeutic target in AML [90]. The role of autophagy in AML is complex. Autophagy is often reduced in human AML cells and the loss of key autophagy genes leads to leukemia initiation and progression in mouse models [91]. On the other hand, autophagy seems important for the pro-survival protection of AML cells, and exposure of the leukemic cells to antileukemic drugs (i.e., cytarabine, anthracyclines and sorafenib) seems to activate and increases autophagic flux and thereby allowing them to resist chemotherapy [92-95]. These different roles suggest that the effect of therapeutic targeting of autophagy in human AML will differ between patients, and this is also consistent with our present data.

Upregulated iron transport and vesicle proteins were enriched in REL_FREE patients. In an independent study, AML patients with high constitutive cytokine release showed increased mRNA expression of proteins involved in intracellular iron homeostasis and molecular trafficking [66]. Interestingly, the overall survival after intensive chemotherapy was significantly higher for high-release compared with low-release AML patients. These results provided confidence and an internal validation of our approach. 
Alignment of sequences surrounding phosphorylation sites and KSEA analysis of our full phosphoproteomics dataset showed an enrichment of phosphorylated substrate groups of MAPK, CSK2, CDK, PAK, PRKC and AKT kinases. We additionally observed that RELAPSE cells had higher activity of CDK2 and higher expression, based on immunoblotting assays, compared to REL_FREE cells. As similarly demonstrated previously, KSEA of phosphoproteome data of AML-derived cells from 20 patients had similar enrichment of CSK2, CDK, PAK, AKT, ABL, SRC, MAPK, PRKA and PRKC kinases, relative to normal peripheral blood stem CD34 ${ }^{+}$cells from five healthy donors [45]. Thus, two independent phosphoproteomics studies on different AML patient cohorts have identified similar sets of kinase upregulations in AML.

The CSK2 inhibitor CX-4945 had a stronger antiproliferative effect for REL_FREE cells than for RELAPSE cells, when acting alone or in combination with CDK inhibitors. Further studies are required to determine whether RELAPSE cells owe their higher CSK2 inhibitor resistance to generally increased robustness or to the lower turnover of CSK2-mediated phosphorylation. Comprehensive KSEA, sequence logos and antibody blotting analyses show that CSK2 and CDKs could be suggested as strong RELAPSE promoters. CSK2, in particular, is a key regulator of several signaling networks and is overexpressed in many hematological cancers [96]. The activity of CDK2 (and potentially also CDK4, CDK6, CDK7 and CDK9) in RELAPSE patients may further increase AML cell proliferation by triggering G1-S-phase transitions [97].

Several phosphoproteins were multi-phosphorylated, like BCL11A with several phosphosites upregulated in the RELAPSE group (S205, T208, S608, S625, S630 and S718). BCL11A, a transcription factor associated with the BAF SWI/SNF chromatin remodeling complex, may play a role in leukemogenesis [98] and its expression is associated with adverse outcome in AML [99]. In a previous phosphoproteomics study with AML patients treated with the FLT3 inhibitor quizartinib, increased phosphorylation of BCL11A S630 was associated with non-responsiveness [27]. Taken together, these results suggest that BCL11A phosphorylation contributes to chemoresistance in AML. TP53BP1, another multi-phosphorylated protein in RELAPSE patients, is a double-strand DNA break repair protein that is phosphorylated at multiple sites in response to DNA damage. Moreover, phosphorylation at S1219 by ATM kinase seems to be a response to ionizing radiation [100]. The S523Q motif might also serve as substrate for ATM kinase and being part of the RIF1, a non-homologous end joining-mediated repair protein, recruitment process to DNA break sites [101].

The stimulatory T190 and T191 phosphosites in the activation loop of NEK7 showed increased phosphorylation in the REL_FREE patients. NEK7 seems to be involved in the recruitment of centrosomal pericentriolar proteins that are necessary for centriole duplication and spindle pole formation during mitosis [102]. Chromosomal lagging, micronuclei formation, cytokinesis failure and tetraploidy/aneuploidy were observed in NEK7 deficient mouse embryonic fibroblasts [103]. Therefore, deregulation of NEK7 activity in cell division processes might contribute to aberrant mitosis and induction of the relapse status [104]. Furthermore, we found two phosphosites, S372 and S389, in the ribosomal S6 kinase RPS6KA1 isoform 2 (Uniprot identifier: Q15418-2), upregulated in REL_FREE patients. It has been reported that phosphorylation at S372 and S389, possibly by PRKC activators, switched on the RPS6KA1 N-terminal kinase domain required for phosphorylation of its substrates [105]. The role of ribosomal S6 kinases in cancer is not well understood and seems to vary by cancer type. While some isoforms of ribosomal $\mathrm{S} 6$ kinases can promote cell motility and invasion processes by altering transcription and integrin activity, others depress them by interacting with the actin cytoskeleton [106]. The fact that the phosphosites of RPS6KA1 might be phosphorylated by NEK7 [104], and not by MTOR, might explain the benefits of higher phosphorylation of membrane, actin filament and cell-cell adherens junction proteins in the REL_FREE group. Our findings encourage functional studies to understand the role of NEK7, PRKC and RPS6KA1 kinases in the cytoskeleton of AML cells.

Finally, although the time intervals to define early or late relapse are debatable [41,42], we subclassified the 26 RELAPSE into 14 EARLY RELAPSE and 12 LATE RELAPSE patients, after setting 
up 12 months from diagnosis to relapse as the mark time to differentiate the two groups. Our results showed that the rRNA processing and V-ATPase clusters (identified when all the 26 RELAPSE patients were included) mainly described the proteome landscape at diagnosis for both the EARLY RELAPSE vs. REL_FREE and LATE RELAPSE vs. REL_FREE subsets. Thus, the AML proteome at diagnosis for patients with either an early or late relapse does not seem to change dramatically. In contrast, the different AML phosphoproteome landscapes at diagnosis described in the EARLY RELAPSE vs. REL_FREE and LATE RELAPSE vs. REL_FREE subsets appear to be influenced by the relapse-free time of RELAPSE patients. Our results, considering all the 26 RELAPSE patients, are valuable for therapy decisions at diagnosis. Nonetheless, further studies with diagnostic and relapsed samples at early and late relapsing episodes might better describe the role of different AML relapse determinants.

\section{Materials and Methods}

\subsection{AML Patients and Sample Collection}

Written informed consent was obtained from all patients in accordance with the Declaration of Helsinki, and the use of human leukemia cells for the present study was approved by the Regional Ethics Committee (REK III Vest 2013-634). Primary AML cells were collected from the peripheral blood of 41 patients with relatively high levels of circulating leukemia blasts ( $>80 \%$ of circulating leukocytes) at the first time of diagnosis, prior to any antileukemic therapy. The peripheral blood leukocyte counts are given in Table S1. Six of the patients had leukocyte counts exceeding $100 \times 10^{9} / \mathrm{L}$ and six additional patients had leukocyte counts between $50-100 \times 10^{9} / \mathrm{L}$, whereas most patients had leukocyte counts below $50 \times 10^{9} / \mathrm{L}$. Peripheral blood samples were collected on ACD tubes and highly enriched AML cell populations (generally $>95 \%$ ) could then be prepared by density gradient separation alone (Lymphoprep, Axis-Shield, specific density 1.077) [107]. The gradient separation and cryopreservation were done immediately after sampling, by using the same standardized method for all patients [31]. Cells were stored in liquid nitrogen until used in the experiments. Flow cytometric analyses showed that the main contaminating cell population, as expected, was small lymphocytes.

Our department is responsible for the diagnosis and initiation of intensive antileukemic treatment for all AML patients in a defined geographical area. The patients in the present study represent all patients within this area and time period who (i) either completed their planned intensive induction and consolidation therapy or died from primary resistant AML/early chemoresistant relapse during treatment, (ii) had a high percentage of circulation AML cells in peripheral blood, and (iii) had an observation time of at least five years. Patients dying from or ending the planned antileukemic therapy due to severe treatment-related toxicity were not included in our present study. Our patients could therefore be classified into two contrasting groups: 15 patients were classified as relapse-free based on the long follow-up period (i.e., REL_FREE patients) and 26 patients as chemoresistant/relapse patients (i.e., RELAPSE patients), including all patients with primary resistant, early relapse during initial chemotherapy or late relapse after completed consolidation therapy. Some of the patients in this last group later received allogeneic stem cell transplantation.

We compared AML cells derived at the first time of diagnosis prior to any antileukemic treatment (see Supplementary methods) for the two contrasting patient groups, and the samples did not differ in storage time or the peripheral blood leukocyte counts of the patients at the time of first diagnosis/sampling. Additional and more detailed patient information is given in Figure 1a,b, Table 1 and Table S1, including the results from karyotyping and mutational analysis of 54 genes frequently mutated in AML. The method for mutational analyses has been described previously [108]. Mutations were classified according to their biological function [34].

Nine additional AML patients were included in validation studies and are described in detail in Table S2. 


\subsection{AML Super-SILAC Mix}

An AML spike-in reference was generated by combining Arg6- and Lys8-labeled protein lysates from five heterogeneous AML-derived cell lines, according to the super-SILAC mix approach $[30,109]$. The spike-in reference was added to each patient sample in a 1:2 ratio (w:w; super-SILAC mix:AML patient sample) for SILAC-based quantitation.

\subsection{Patient Sample Preparation for Proteomic and Phosphoproteomic Analysis}

Sample preparation of patient cell lysate in $4 \%$ sodium dodecyl sulfate (SDS)/0.1 M Tris-HCl ( $\mathrm{pH}$ 7.6) and immobilized metal affinity chromatography (IMAC) has been described earlier [32]. Briefly, $20 \mu \mathrm{g}$ of each patient lysate was prepared both as 1) a label-free sample and 2) mixed with $10 \mu \mathrm{g}$ of the super-SILAC mix for proteomic analyses, and processed according to the FASP protocol (Figure 1c) [32,110]. Only the super-SILAC spiked peptide samples were fractionated using styrenedivinylbenzene-reversed phase sulfonate (SDB-RPS) plugs (Empore, 3M) [111]. The phosphoproteomics samples (64-1121 $\mu \mathrm{g}$ range) were mixed with the super-SILAC mix at the ratio described before, FASP processed and enriched for phosphopeptides using the IMAC procedure.

\subsection{Nanoflow LC-MS/MS}

Peptide sample preparation prior to LC-MS/MS and settings of the LC-MS/MS runs on a $\mathrm{Q}$ Exactive HF Orbitrap mass spectrometer coupled to an Ultimate 3000 Rapid Separation LC system (Thermo Scientific, Waltham, MA, USA) were conducted as described earlier for global proteomics [112] and phosphoproteomics [32], and detailed in Supplementary Methods.

\subsection{Data and Bioinformatics Analysis}

LC-MS/MS raw files from RELAPSE and REL_FREE samples were processed with MaxQuant software version 1.5.2.8 (see Supplementary methods) $[113,114]$. The spectra were searched against the concatenated forward and reversed-decoy Swiss-Prot Homo sapiens database version 2018_02, using the Andromeda search engine [115]. The LC-MS/MS raw files and MaxQuant output files have been deposited to the ProteomeXchange consortium via the PRIDE partner repository [116,117] with dataset identifier PXD014997. The Perseus 1.6.1.1 platform was used to analyze and visualize protein groups and phosphosites [118]. MaxQuant-normalized SILAC ratios were inverted, $\log _{2}$ transformed and normalized again, using width adjustment. Proteins and phosphosites (localization probability $>0.75$ ) with at least five individual SILAC ratios in each patient group were selected for two-sample unequal variance $t$-test and Z-statistics [119] to find significantly different FC for proteins and phosphosites between the RELAPSE and REL_FREE groups. Hierarchical clustering of significantly differential proteins and phosphosites was done with Perseus using the Pearson correlation function and complete linkage. GO analysis was performed using a GO tool [120]. The most significantly over-represented GO terms with FDR $<0.05$ were displayed in bar plots in Prism8 (GraphPad). Venn diagrams were made with Venny 2.1 (Oliveros, J.C., http://bioinfogp.cnb.csic.es/tools/venny/index.html) or BioVenn [121]. GSEA (http://software.broadinstitute.org/gsea/index.jsp) was performed against the Hallmark gene set collection of the Molecular Signatures Database v6.2 [122]. The amino acid distribution surrounding the phosphosites was analyzed using iceLogo $(p=0.05)$, with the sequence windows obtained in the MaxQuant-generated phosphosite output file [43]. Unregulated phosphosites were used as a reference set. Sequence logo analyses from a small number of phosphopeptide sequences were generated with WebLogo [46]. Kinase activity estimates were inferred by the KSEA App. [44,45]. Regulated and unregulated phosphosites were analyzed with the PhosphoSitePlus [123] and NetworKin [124] databases, using a substrate count and a NetworKin score cutoff of 5 . Significantly regulated kinases with Benjamini-Hochberg adjusted $p<0.05$ were showed in bar plots. Kinase activation loop analysis was performed with the tools for phosphoproteomics data analysis at http://phomics.jensenlab.org. PPI networks were obtained by using the STRING database version 10.5, with interactions derived 
from experiments and databases at a high confidence score of 0.7 [125]. Networks were visualized using the Cytoscape platform version 3.3.0 [126]. The ClusterONE plugin was used to identify protein groups of high cohesiveness [127].

\subsection{Enrichment Analysis of Transcription Proteins Binding Sites}

Putative binding sites of transcription proteins were found by analyzing public available ChIP-seq data on K562 cell line (derived from a patient with blast phase chronic myeloid leukemia; an undifferentiated myeloid cell line also expressing certain erythroid markers $[128,129])$ at the ENCODE project [130]. ENCODE accession IDs of files are provided in Table S3. Sequencing reads were downloaded and aligned to human genome hg19 using Bowtie 2.2.9 [131]. Aligned reads were subjected to peak calling using MACS and annotated using Homer following methods published previously [132-136]. Peak information of the putative targets was analyzed by the BETA algorithm in Cistrome analysis pipeline (http://cistrome.org/ap/root) [137]. A GO enrichment analysis of putative target genes was carried out using DAVID with default parameters $[138,139]$. Significantly over-represented GO terms with Benjamini-Hochberg adjusted $p<0.05$ were displayed in bar plots.

\subsection{Cell Proliferation Assay}

The cytokine-dependent in vitro proliferation of enriched AML cells was analyzed by a $3 \mathrm{H}$-thymidine incorporation assay [56]. Cryopreserved primary cells were thawed in a water bath set at $37^{\circ} \mathrm{C}$ and diluted 1:1 with RPMI, containing $2 \mathrm{mM}$ L-glutamine and penstrap. The cells were incubated at room temperature for $5 \mathrm{~min}$ and extra RPMI solution (same volume of the original cells) was added. The cells were centrifuged at $250 \times \mathrm{g}$ at room temperature for $8 \mathrm{~min}$ and the pellet was resuspended in $4.5 \mathrm{~mL}$ of the RPMI solution. After counting the cells with trypan blue, the AML cells were seeded in flat-bottomed 96-well microtiter plates (VWR ${ }^{\circledR}$, Lutterworth, UK), with a seeding density of 50,000 cells/well ( $200 \mu \mathrm{L}$ medium/well). The culture medium was Stem Span SFEM ${ }^{\mathrm{TM}}$ (Stem Cell Technologies, Vancouver, Canada), supplemented with granulocyte-macrophage stimulating factor (GM-CSF), FLT3 ligand (FLT3-L) and stem cell factor (SCF); all cytokines were purchased from PeproTech (Rocky Hill, NJ, USA) and used at a final concentration of $20 \mathrm{ng} / \mathrm{mL}$. The cells were treated with 0 (control), 1, 5 and 10 nM BafA1 (Streptomyces griseus-CAS 88899-55-2-Calbiochem, now Sigma-Aldrich, St. Louis, MO, USA) and the kinase inhibitors (Selleckchem, Houston, TX, USA) at concentrations indicated in Table S5. All the inhibitors used in this study are well characterized and more detailed information including clinical trials is available in the PubChem database [140]. After six days of culture, $37 \mathrm{kBq}$ of ${ }^{3} \mathrm{H}$-thymidine (Perkin Elmer, Waltham, MA, USA) was added to each well and the cells were further incubated for 18-20 h, before being harvested and nuclear radioactivity being measured. For cell viability assay of cells treated with $10 \mathrm{nM}$ BafA1 and control, primary cells were cultured for $48 \mathrm{~h}$ in flat-bottomed 24-well culture plates $\left(\mathrm{VWR}^{\circledR}\right)\left(1 \times 10^{6}\right.$ cells $/ \mathrm{mL}, 1 \mathrm{~mL} /$ well), using the same medium as described above. The cells were labeled with propidium iodide and fluorescein isothiocyanate-conjugated Annexin V (Tau Technologies BV, Kattendijke, The Netherlands), prior to flow cytometry analysis. The percentage of viable, apoptotic and necrotic cells was determined. The median of triplicate determinations was used in all analyses. A Mann-Whitney U test (SPSS Statistics v.25, IBM, Armonk, NY, USA) was employed for the analysis of differences between different groups and Wilcoxon's matched-pair signed rank test (SPSS Statistics v.25) for the analysis of differences between paired samples.

\subsection{Western Blots}

Western blots for three RELAPSE and three REL_FREE patient cells used in the cell proliferation assay and incubated with kinase inhibitors at $37^{\circ} \mathrm{C}$ for $15 \mathrm{~min}$ were performed. Control and treated patient primary cells were centrifuged at $270 \times g$ at $4{ }^{\circ} \mathrm{C}$ for $5 \mathrm{~min}$ and washed with a solution of $\mathrm{NaCl}$ $(9 \mathrm{mg} / \mathrm{mL}$ ) on ice. After the centrifugation step, $100 \mu \mathrm{L}$ of $4 \% \mathrm{SDS} / 0.1 \mathrm{M}$ Tris- $\mathrm{HCl}$ (pH 7.6) were added to the cell pellets. The samples were heated at $95^{\circ} \mathrm{C}$ for $7 \mathrm{~min}$ and kept in the freezer. Twenty-five 
$\mu \mathrm{g}$ of each sample was loaded on a NuPAGE 4-12\% Bis-Tris protein gel (ThemoFisher Scientific) and transferred onto a nitrocellulose membrane (Amersham Protran, GE Healthcare Life Sciences, Chicago, IL, USA) in an XCell II Blot Module (ThermoFisher Scientific). Antibodies were purchased from Cell Signaling Technology (Danvers, MA, USA) and used according to the manufacturer's guidelines. Chemiluminescence was measured on a LAS-3000 imager (Fujifilm, Tokyo, Japan). Band intensities for each protein were determined by densitometry software Image J (Table S6) [141]. Band intensities of a protein spotted at approximately $17 \mathrm{kDa}$ on Ponceau-stained membranes were used for normalization (Figure S13a, Table S6). Statistical analysis was performed using unpaired $t$-test.

\section{Conclusions}

This study describes the proteomics profiles of patient-derived AML cells collected at the first time of diagnosis that differ between patients that are long-term relapse free survivors and patients that relapse. The relapse-associated group displayed decreased expression of V-ATPases and the increased activity of CDKs and CSK2. Furthermore, our results suggest a subset of transcriptional and metabolic regulators that could be considered as predictors of prognosis and therapeutic targets in AML.

Supplementary Materials: The following are available online at http://www.mdpi.com/2072-6694/12/3/709/s1, Supplementary methods with more explanations on the treatment of AML patients, LC-MS/MS analysis of the AML proteome and phosphoproteome, and MaxQuant analysis of SILAC-labeled and label-free AML samples. Supplementary data showing the comparison between the proteomics analyses of the datasets produced using the super-SILAC mix and label-free quantification methods. Figure S1: The number of quantified proteins per patient sample is similar with label-free and super-SILAC mix based quantification. Figure S2: The FCs of RELAPSE vs. REL_FREE proteins correlate in the super-SILAC mix and label-free datasets. Figure S3: Clustering performance of 150 proteins validated by label-free proteomics. Figure S4: GSEA analysis. Figure S5: Comparison between the differentially expressed proteins found in the EARLY RELAPSE-REL_FREE and LATE RELAPSE-REL_FREE subcohorts. Figure S6: IceLogos of the 31 amino acid sequence windows surrounding phosphorylation sites (location marked with an arrow). Figure S7: Sequence logo analysis of the 31 amino acid sequence windows surrounding phosphorylation sites (located on position 16 on the $X$ axis) of ClusterOne protein networks showed in Figure 3e on the main text. Figure S8: Significant GO molecular function terms and KEGG pathways of target genes predicted from analysis of ChIP-seq data of transcription proteins. Figure S9: Phosphoproteins with differentially regulated phosphorylation sites in the RELAPSE vs. REL_FREE cohort dataset with unaltered overall expression. Figure S10: Overlap of regulated proteins and phosphoproteins in the RELAPSE vs. REL_FREE cohort study. Figure S11: Comparison between the differentially regulated phosphorylation sites found in the EARLY RELAPSE-REL_FREE and LATE RELAPSE-REL_FREE subcohorts. Figure S12: V-ATPase inhibitor assays. Figure S13: Ponceau-stained membranes and Western blots. Table S1: Overview of the 41 AML patients used in this study. Table S2: Overview of the nine AML patients external to the study cohort used for cell proliferation and Western blot assays. Table S3: List of 14 transcription-related proteins and/or phosphoproteins with higher abundance/phosphorylation in the RELAPSE group subjected to ChIP analysis to determine binding sites of target genes. Table S4: List of overlapping regulated proteins and phosphoproteins in the 26 RELAPSE and 15 REL_FREE patient cohort. Table S5: Cell proliferation assays using kinase inhibitors. Table S6: Densitometry intensities and normalized intensities of Western blot bands. Supplementary References. Supplementary file 1: Proteomics data RELAPSE vs. REL_FREE cohort. Supplementary file 2: Supp information to Figure 2c. Supplementary file 3: Phosphoproteomics data RELAPSE vs. REL_FREE cohort. Supplementary file 4: Kinase substrates.

Author Contributions: E.A., F.S.B., Ø.B., F.S. and M.H.-V. contributed to experimental design and scientific discussion. E.A. and M.H.-V. carried out proteomics and phosphoproteomics experiments. S.B.-B. performed cell proliferation assays. T.S. performed ChIP-seq analyses. R.H. performed mutational studies of the AML patients. Ø.B. provided the AML patient samples. E.A., T.S.B., J.V.O. and M.H.-V. contributed to data analysis. E.M. and M.V. contributed to scientific discussions. E.A., F.S.B., S.O.D., T.S.B., J.V.O., Ø.B., F.S. and M.H.-V. wrote the manuscript. All authors have read and agreed to the published version of the manuscript.

Funding: This work was supported by Kreftforeningen, the Norwegian Cancer Society (grant no. 100933). The Genomics Core Facility (GCF) is supported in part by major grants from the Research Council of Norway (grant no. 245979/F50) and Bergen Research Foundation. Work at The Novo Nordisk Foundation Center for Protein Research (CPR) is funded in part by a generous donation from the Novo Nordisk Foundation (grant no. NNF14CC0001).

Acknowledgments: We thank Hilde Kristin Garberg, Olav Mjaavatten, Marie Hagen, Kristin Rye Paulsen, Atle Brendehaug, Sigrid Erdal, Laura Minsaas, Hans Petter Brodahl and Nina Lied Larsen for excellent technical assistance. The GCF at the University of Bergen, which is part of the NorSeq consortium, provided support in ChIP-Seq bioinformatics analysis.

Conflicts of Interest: The authors declare no conflict of interest. 


\section{References}

1. Ferrara, F.; Schiffer, C.A. Acute myeloid leukaemia in adults. Lancet 2013, 381, 484-495. [CrossRef]

2. Arber, D.A.; Orazi, A.; Hasserjian, R.; Thiele, J.; Borowitz, M.J.; Le Beau, M.M.; Bloomfield, C.D.; Cazzola, M.; Vardiman, J.W. The 2016 revision to the World Health Organization classification of myeloid neoplasms and acute leukemia. Blood 2016, 127, 2391-2405. [CrossRef]

3. Sanz, M.A.; Fenaux, P.; Tallman, M.S.; Estey, E.H.; Lowenberg, B.; Naoe, T.; Lengfelder, E.; Dohner, H.; Burnett, A.K.; Chen, S.J.; et al. Management of acute promyelocytic leukemia: Updated recommendations from an expert panel of the European LeukemiaNet. Blood 2019, 133, 1630-1643. [CrossRef] [PubMed]

4. Döhner, H.; Estey, E.H.; Amadori, S.; Appelbaum, F.R.; Büchner, T.; Burnett, A.K.; Dombret, H.; Fenaux, P.; Grimwade, D.; Larson, R.A.; et al. Diagnosis and management of acute myeloid leukemia in adults: Recommendations from an international expert panel, on behalf of the European LeukemiaNet. Blood 2010, 115, 453-474. [CrossRef] [PubMed]

5. Cornelissen, J.J.; Gratwohl, A.; Schlenk, R.F.; Sierra, J.; Bornhäuser, M.; Juliusson, G.; Råcil, Z.; Rowe, J.M.; Russell, N.; Mohty, M.; et al. The European LeukemiaNet AML Working Party consensus statement on allogeneic HSCT for patients with AML in remission: An integrated-risk adapted approach. Nat. Rev. Clin. Oncol. 2012, 9, 579-590. [CrossRef] [PubMed]

6. Estey, E.H. Acute myeloid leukemia: 2014 update on risk-stratification and management. Am. J. Hematol. 2014, 89, 1063-1081. [CrossRef] [PubMed]

7. Ossenkoppele, G.J.; Janssen, J.J.; van de Loosdrecht, A.A. Risk factors for relapse after allogeneic transplantation in acute myeloid leukemia. Haematologica 2016, 101, 20-25. [CrossRef] [PubMed]

8. Döhner, H.; Estey, E.; Grimwade, D.; Amadori, S.; Appelbaum, F.R.; Büchner, T.; Dombret, H.; Ebert, B.L.; Fenaux, P.; Larson, R.A.; et al. Diagnosis and management of AML in adults: 2017 ELN recommendations from an international expert panel. Blood 2017, 129, 424-447. [CrossRef] [PubMed]

9. Irish, J.M.; Anensen, N.; Hovland, R.; Skavland, J.; Borresen-Dale, A.L.; Bruserud, O.; Nolan, G.P.; Gjertsen, B.T. Flt3 Y591 duplication and Bc1-2 overexpression are detected in acute myeloid leukemia cells with high levels of phosphorylated wild-type p53. Blood 2007, 109, 2589-2596. [CrossRef]

10. Nepstad, I.; Hatfield, K.J.; Tvedt, T.H.A.; Reikvam, H.; Bruserud, O. Clonal Heterogeneity Reflected by PI3K-AKT-mTOR Signaling in Human Acute Myeloid Leukemia Cells and Its Association with Adverse Prognosis. Cancers 2018, 10, 332. [CrossRef]

11. Patel, J.P.; Gönen, M.; Figueroa, M.E.; Fernandez, H.; Sun, Z.; Racevskis, J.; Van Vlierberghe, P.; Dolgalev, I.; Thomas, S.; Aminova, O.; et al. Prognostic relevance of integrated genetic profiling in acute myeloid leukemia. N. Engl. J. Med. 2012, 366, 1079-1089. [CrossRef] [PubMed]

12. Papaemmanuil, E.; Gerstung, M.; Bullinger, L.; Gaidzik, V.I.; Paschka, P.; Roberts, N.D.; Potter, N.E.; Heuser, M.; Thol, F.; Bolli, N.; et al. Genomic Classification and Prognosis in Acute Myeloid Leukemia. N. Engl. J. Med. 2016, 374, 2209-2221. [CrossRef] [PubMed]

13. Bullinger, L.; Dohner, K.; Dohner, H. Genomics of Acute Myeloid Leukemia Diagnosis and Pathways. J. Clin. Oncol. 2017, 35, 934-946. [CrossRef] [PubMed]

14. Cancer Genome Atlas Research Network. Genomic and epigenomic landscapes of adult de novo acute myeloid leukemia. N. Engl. J. Med. 2013, 368, 2059-2074. [CrossRef] [PubMed]

15. Corces, M.R.; Chang, H.Y.; Majeti, R. Preleukemic Hematopoietic Stem Cells in Human Acute Myeloid Leukemia. Front. Oncol. 2017, 7, 263. [CrossRef]

16. Medeiros, B.C.; Minden, M.D.; Schuh, A.C.; Schimmer, A.D.; Yee, K.; Lipton, J.H.; Messner, H.A.; Gupta, V.; Chun, K.; Xu, W.; et al. Characteristics and outcomes of acute myelogenous leukemia patients with very late relapse (>5 years). Leuk. Lymphoma 2007, 48, 65-71. [CrossRef]

17. Pedersen-Bjergaard, J.; Andersen, M.T.; Andersen, M.K. Genetic pathways in the pathogenesis of therapy-related myelodysplasia and acute myeloid leukemia. Hematol. Am. Soc. Hematol. Educ. Progr. 2007. [CrossRef] [PubMed]

18. Cocciardi, S.; Dolnik, A.; Kapp-Schwoerer, S.; Rucker, F.G.; Lux, S.; Blatte, T.J.; Skambraks, S.; Kronke, J.; Heidel, F.H.; Schnoder, T.M.; et al. Clonal evolution patterns in acute myeloid leukemia with NPM1 mutation. Nat. Commun. 2019, 10, 2031. [CrossRef] [PubMed] 
19. Hollein, A.; Meggendorfer, M.; Dicker, F.; Jeromin, S.; Nadarajah, N.; Kern, W.; Haferlach, C.; Haferlach, T. NPM1 mutated AML can relapse with wild-type NPM1: Persistent clonal hematopoiesis can drive relapse. Blood Adv. 2018, 2, 3118-3125. [CrossRef]

20. Greif, P.A.; Hartmann, L.; Vosberg, S.; Stief, S.M.; Mattes, R.; Hellmann, I.; Metzeler, K.H.; Herold, T.; Bamopoulos, S.A.; Kerbs, P.; et al. Evolution of Cytogenetically Normal Acute Myeloid Leukemia During Therapy and Relapse: An Exome Sequencing Study of 50 Patients. Clin. Cancer Res. 2018, 24, 1716-1726. [CrossRef] [PubMed]

21. Vosberg, S.; Greif, P.A. Clonal evolution of acute myeloid leukemia from diagnosis to relapse. Genes Chromosomes Cancer 2019, 58, 839-849. [CrossRef] [PubMed]

22. Yilmaz, M.; Wang, F.; Loghavi, S.; Bueso-Ramos, C.; Gumbs, C.; Little, L.; Song, X.Z.; Zhang, J.H.; Kadia, T.; Borthakur, G.; et al. Late relapse in acute myeloid leukemia (AML): Clonal evolution or therapy-related leukemia? Blood Cancer J. 2019, 9. [CrossRef] [PubMed]

23. Aasebø, E.; Forthun, R.B.; Berven, F.; Selheim, F.; Hernandez-Valladares, M. Global Cell Proteome Profiling, Phospho-signaling and Quantitative Proteomics for Identification of New Biomarkers in Acute Myeloid Leukemia Patients. Curr. Pharm. Biotechnol. 2016, 17, 52-70. [CrossRef] [PubMed]

24. Foss, E.J.; Radulovic, D.; Stirewalt, D.L.; Radich, J.; Sala-Torra, O.; Pogosova-Agadjanyan, E.L.; Hengel, S.M.; Loeb, K.R.; Deeg, H.J.; Meshinchi, S.; et al. Proteomic classification of acute leukemias by alignment-based quantitation of LC-MS/MS data sets. J. Proteome Res. 2012, 11, 5005-5010. [CrossRef]

25. Forthun, R.B.; Aasebø, E.; Rasinger, J.D.; Bedringaas, S.L.; Berven, F.; Selheim, F.; Bruserud, Ø.; Gjertsen, B.T. Phosphoprotein DIGE profiles reflect blast differentiation, cytogenetic risk stratification, FLT3/NPM1 mutations and therapy response in acute myeloid leukaemia. J. Proteom. 2018, 173, 32-41. [CrossRef]

26. Wojtuszkiewicz, A.; Schuurhuis, G.J.; Kessler, F.L.; Piersma, S.R.; Knol, J.C.; Pham, T.V.; Jansen, G.; Musters, R.J.; van Meerloo, J.; Assaraf, Y.G.; et al. Exosomes Secreted by Apoptosis-Resistant Acute Myeloid Leukemia (AML) Blasts Harbor Regulatory Network Proteins Potentially Involved in Antagonism of Apoptosis. Mol. Cell. Proteom. 2016, 15, 1281-1298. [CrossRef]

27. Schaab, C.; Oppermann, F.S.; Klammer, M.; Pfeifer, H.; Tebbe, A.; Oellerich, T.; Krauter, J.; Levis, M.; Perl, A.E.; Daub, H.; et al. Global phosphoproteome analysis of human bone marrow reveals predictive phosphorylation markers for the treatment of acute myeloid leukemia with quizartinib. Leukemia 2014, 28, 716-719. [CrossRef]

28. Tong, J.; Helmy, M.; Cavalli, F.M.; Jin, L.; St-Germain, J.; Karisch, R.; Taylor, P.; Minden, M.D.; Taylor, M.D.; Neel, B.G.; et al. Integrated analysis of proteome, phosphotyrosine-proteome, tyrosine-kinome, and tyrosine-phosphatome in acute myeloid leukemia. Proteomics 2017, 17. [CrossRef]

29. Casado, P.; Wilkes, E.H.; Miraki-Moud, F.; Hadi, M.M.; Rio-Machin, A.; Rajeeve, V.; Pike, R.; Iqbal, S.; Marfa, S.; Lea, N.; et al. Proteomic and genomic integration identifies kinase and differentiation determinants of kinase inhibitor sensitivity in leukemia cells. Leukemia 2018, 32, 1818-1822. [CrossRef]

30. Aasebø, E.; Vaudel, M.; Mjaavatten, O.; Gausdal, G.; Van der Burgh, A.; Gjertsen, B.T.; Døskeland, S.O.; Bruserud, Ø.; Berven, F.S.; Selheim, F. Performance of super-SILAC based quantitative proteomics for comparison of different acute myeloid leukemia (AML) cell lines. Proteomics 2014, 14, 1971-1976. [CrossRef]

31. Aasebø, E.; Mjaavatten, O.; Vaudel, M.; Farag, Y.; Selheim, F.; Berven, F.; Bruserud, Ø.; Hernandez-Valladares, M. Freezing effects on the acute myeloid leukemia cell proteome and phosphoproteome revealed using optimal quantitative workflows. J. Proteom. 2016, 145, 214-225. [CrossRef] [PubMed]

32. Hernandez-Valladares, M.; Aasebø, E.; Mjaavatten, O.; Vaudel, M.; Bruserud, Ø.; Berven, F.; Selheim, F. Reliable FASP-based procedures for optimal quantitative proteomic and phosphoproteomic analysis on samples from acute myeloid leukemia patients. Biol. Proced. Online 2016, 18, 13. [CrossRef] [PubMed]

33. Hernandez-Valladares, M.; Aasebo, E.; Selheim, F.; Berven, F.S.; Bruserud, O. Selecting Sample Preparation Workflows for Mass Spectrometry-Based Proteomic and Phosphoproteomic Analysis of Patient Samples with Acute Myeloid Leukemia. Proteomes 2016, 4, 24. [CrossRef] [PubMed]

34. Reikvam, H.; Aasebo, E.; Brenner, A.K.; Bartaula-Brevik, S.; Gronningsaeter, I.S.; Forthun, R.B.; Hovland, R.; Bruserud, O. High Constitutive Cytokine Release by Primary Human Acute Myeloid Leukemia Cells Is Associated with a Specific Intercellular Communication Phenotype. J. Clin. Med. 2019, 8, 970. [CrossRef]

35. Tsykunova, G.; Reikvam, H.; Hovland, R.; Bruserud, O. The surface molecule signature of primary human acute myeloid leukemia (AML) cells is highly associated with NPM1 mutation status. Leukemia 2012, 26, 557-559. [CrossRef] 
36. Stransky, L.; Cotter, K.; Forgac, M. The Function of V-Atpases in Cancer. Physiol. Rev. 2016, 96, $1071-1091$. [CrossRef]

37. Bammert, L.; Jonas, S.; Ungricht, R.; Kutay, U. Human AATF/Che-1 forms a nucleolar protein complex with NGDN and NOL10 required for 40S ribosomal subunit synthesis. Nucleic Acids Res. 2016, 44, 9803-9820. [CrossRef]

38. Folgiero, V.; Sorino, C.; Locatelli, F.; Fanciulli, M. A new baby in the c-Myc-directed transcriptional machinery: Che-1/AATF. Cell Cycle 2018, 17, 1286-1290. [CrossRef]

39. Kaul, D.; Mehrotra, A. Functional characterization of AATF transcriptome in human leukemic cells. Mol. Cell. Biochem. 2007, 297, 215-220. [CrossRef]

40. Liberzon, A.; Birger, C.; Thorvaldsdottir, H.; Ghandi, M.; Mesirov, J.P.; Tamayo, P. The Molecular Signatures Database (MSigDB) hallmark gene set collection. Cell Syst. 2015, 1, 417-425. [CrossRef]

41. Breems, D.A.; Van Putten, W.L.; Huijgens, P.C.; Ossenkoppele, G.J.; Verhoef, G.E.; Verdonck, L.F.; Vellenga, E.; De Greef, G.E.; Jacky, E.; Van der Lelie, J.; et al. Prognostic index for adult patients with acute myeloid leukemia in first relapse. J. Clin. Oncol. 2005, 23, 1969-1978. [CrossRef] [PubMed]

42. Short, N.J.; Rytting, M.E.; Cortes, J.E. Acute myeloid leukaemia. Lancet 2018, 392, 593-606. [CrossRef]

43. Colaert, N.; Helsens, K.; Martens, L.; Vandekerckhove, J.; Gevaert, K. Improved visualization of protein consensus sequences by iceLogo. Nat. Methods 2009, 6, 786-787. [CrossRef]

44. Wiredja, D.D.; Koyuturk, M.; Chance, M.R. The KSEA App: A web-based tool for kinase activity inference from quantitative phosphoproteomics. Bioinformatics 2017, 33, 3489-3491. [CrossRef] [PubMed]

45. Casado, P.; Rodriguez-Prados, J.C.; Cosulich, S.C.; Guichard, S.; Vanhaesebroeck, B.; Joel, S.; Cutillas, P.R. Kinase-substrate enrichment analysis provides insights into the heterogeneity of signaling pathway activation in leukemia cells. Sci. Signal. 2013, 6, rs6. [CrossRef] [PubMed]

46. Crooks, G.E.; Hon, G.; Chandonia, J.M.; Brenner, S.E. WebLogo: A sequence logo generator. Genome Res. 2004, 14, 1188-1190. [CrossRef]

47. Negi, S.S.; Olson, M.O. Effects of interphase and mitotic phosphorylation on the mobility and location of nucleolar protein B23. J. Cell Sci. 2006, 119, 3676-3685. [CrossRef]

48. Zou, Y.; Jiang, X.; Wang, Y. Identification of novel in vivo phosphorylation sites in high mobility group N1 protein from the MCF-7 human breast cancer cells. Biochemistry 2004, 43, 6322-6329. [CrossRef]

49. Beausoleil, S.A.; Jedrychowski, M.; Schwartz, D.; Elias, J.E.; Villen, J.; Li, J.; Cohn, M.A.; Cantley, L.C.; Gygi, S.P. Large-scale characterization of HeLa cell nuclear phosphoproteins. Proc. Natl. Acad. Sci. USA 2004, 101, 12130-12135. [CrossRef]

50. Misra, R.N.; Xiao, H.Y.; Kim, K.S.; Lu, S.F.; Han, W.C.; Barbosa, S.A.; Hunt, J.T.; Rawlins, D.B.; Shan, W.F.; Ahmed, S.Z; i et al. N-(Cycloalkylamino)acyl-2-aminothiazole inhibitors of cyclin-dependent kinase-2. $\mathrm{N}$-[5-[[[5-(1,1-dimethylethyl)-2-oxazolyl]methyl]thio]-2-thiazolyl]-4-piperidinecarboxamide (BMS-387032), a highly efficacious and selective antitumor agent. J. Med. Chem. 2004, 47, 1719-1728. [CrossRef]

51. Lemke, J.; von Karstedt, S.; Abd El Hay, M.; Conti, A.; Arce, F.; Montinaro, A.; Papenfuss, K.; El-Bahrawy, M.A.; Walczak, H. Selective CDK9 inhibition overcomes TRAIL resistance by concomitant suppression of cFlip and Mcl-1. Cell Death Differ. 2014, 21, 491-502. [CrossRef] [PubMed]

52. Xie, G.; Tang, H.; Wu, S.; Chen, J.; Liu, J.; Liao, C. The cyclin-dependent kinase inhibitor SNS-032 induces apoptosis in breast cancer cells via depletion of Mcl-1 and X-linked inhibitor of apoptosis protein and displays antitumor activity in vivo. Int. J. Oncol. 2014, 45, 804-812. [CrossRef] [PubMed]

53. Jha, S.; Morris, E.J.; Hruza, A.; Mansueto, M.S.; Schroeder, G.K.; Arbanas, J.; McMasters, D.; Restaino, C.R.; Dayananth, P.; Black, S.; et al. Dissecting Therapeutic Resistance to ERK Inhibition. Mol. Cancer Ther. 2016, 15, 548-559. [CrossRef] [PubMed]

54. Gjertsen, B.T.; Øyan, A.M.; Marzolf, B.; Hovland, R.; Gausdal, G.; Døskeland, S.O.; Dimitrov, K.; Golden, A.; Kalland, K.H.; Hood, L.; et al. Analysis of acute myelogenous leukemia: Preparation of samples for genomic and proteomic analyses. J. Hematother. Stem Cell Res. 2002, 11, 469-481. [CrossRef]

55. Bruserud, O.; Tjonnfjord, G.; Gjertsen, B.T.; Foss, B.; Ernst, P. New strategies in the treatment of acute myelogenous leukemia: Mobilization and transplantation of autologous peripheral blood stem cells in adult patients. Stem Cells 2001, 18, 341-351.

56. Bruserud, Ø.; Hovland, R.; Wergeland, L.; Huang, T.S.; Gjertsen, B.T. Flt3-mediated signaling in human acute myelogenous leukemia (AML) blasts: A functional characterization of Flt3-ligand effects in AML cell populations with and without genetic Flt3 abnormalities. Haematologica 2003, 88, 416-428. 
57. Hu, C.W.; Qiu, Y.; Ligeralde, A.; Raybon, A.Y.; Yoo, S.Y.; Coombes, K.R.; Qutub, A.A.; Kornblau, S.M. A quantitative analysis of heterogeneities and hallmarks in acute myelogenous leukaemia. Nat. Biomed. Eng. 2019, 3, 889-901. [CrossRef]

58. Wheatley, K.; Burnett, A.K.; Goldstone, A.H.; Gray, R.G.; Hann, I.M.; Harrison, C.J.; Rees, J.K.H.; Stevens, R.F.; Walker, H. A simple, robust, validated and highly predictive index for the determination of risk-directed therapy in acute myeloid leukaemia derived from the MRC AML 10 trial. Br. J. Haematol. 1999, 107, 69-79. [CrossRef]

59. de Jonge, H.J.M.; Valk, P.J.M.; de Bont, E.S.J.M.; Schuringa, J.J.; Ossenkoppele, G.; Vellenga, E.; Huls, G. Prognostic impact of white blood cell count in intermediate risk acute myeloid leukemia: Relevance of mutated NPM1 and FLT3-ITD. Haematologica 2011, 96, 1310-1317. [CrossRef]

60. Lin, P.; Chen, L.; Luthra, R.; Konoplev, S.N.; Wang, X.M.; Medeiros, L.J. Acute myeloid leukemia harboring $\mathrm{t}(8 ; 21)(\mathrm{q} 22 ; \mathrm{q} 22)$ : A heterogeneous disease with poor outcome in a subset of patients unrelated to secondary cytogenetic aberrations. Mod. Pathol. 2008, 21, 1029-1036. [CrossRef]

61. Feng, S.L.; Zhou, L.; Zhang, X.H.; Tang, B.L.; Zhu, X.Y.; Liu, H.L.; Sun, Z.M.; Zheng, C.C. Impact Of ELN Risk Stratification, Induction Chemotherapy Regimens And Hematopoietic Stem Cell Transplantation On Outcomes In Hyperleukocytic Acute Myeloid Leukemia With Initial White Blood Cell Count More Than 100 x 10(9)/L. Cancer Manag. Res. 2019, 11, 9495-9503. [CrossRef] [PubMed]

62. How, J.; Sykes, J.; Gupta, V.; Yee, K.W.; Schimmer, A.D.; Schuh, A.C.; Minden, M.D.; Kamel-Reid, S.; Brandwein, J.M. Influence of FLT3-internal tandem duplication allele burden and white blood cell count on the outcome in patients with intermediate-risk karyotype acute myeloid leukemia. Cancer 2012, 118, 6110-6117. [CrossRef] [PubMed]

63. Reuss-Borst, M.A.; Klein, G.; Waller, H.D.; Muller, C.A. Differential expression of adhesion molecules in acute leukemia. Leukemia 1995, 9, 869-874. [PubMed]

64. Brenner, A.K.; Aasebo, E.; Hernandez-Valladares, M.; Selheim, F.; Berven, F.; Gronningsaeter, I.S.; Bartaula-Brevik, S.; Bruserud, O. The Capacity of Long-Term In Vitro Proliferation of Acute Myeloid Leukemia Cells Supported Only by Exogenous Cytokines Is Associated with a Patient Subset with Adverse Outcome. Cancers 2019, 11, 73. [CrossRef] [PubMed]

65. Nepstad, I.; Reikvam, H.; Brenner, A.K.; Bruserud, O.; Hatfield, K.J. Resistance to the Antiproliferative In Vitro Effect of PI3K-Akt-mTOR Inhibition in Primary Human Acute Myeloid Leukemia Cells Is Associated with Altered Cell Metabolism. Int. J. Mol. Sci. 2018, 19, 382. [CrossRef] [PubMed]

66. Brenner, A.K.; Tvedt, T.H.; Nepstad, I.; Rye, K.P.; Hagen, K.M.; Reikvam, H.; Bruserud, O. Patients with acute myeloid leukemia can be subclassified based on the constitutive cytokine release of the leukemic cells; the possible clinical relevance and the importance of cellular iron metabolism. Expert Opin. Ther. Targets 2017, 21, 357-369. [CrossRef]

67. Bullinger, L.; Dohner, K.; Bair, E.; Frohling, S.; Schlenk, R.F.; Tibshirani, R.; Dohner, H.; Pollack, J.R. Use of gene-expression profiling to identify prognostic subclasses in adult acute myeloid leukemia. N. Engl. J. Med. 2004, 350, 1605-1616. [CrossRef]

68. Heuser, M.; Wingen, L.U.; Steinemann, D.; Cario, G.; von Neuhoff, N.; Tauscher, M.; Bullinger, L.; Krauter, J.; Heil, G.; Dohner, H.; et al. Gene-expression profiles and their association with drug resistance in adult acute myeloid leukemia. Haematologica 2005, 90, 1484-1492.

69. Eppert, K.; Takenaka, K.; Lechman, E.R.; Waldron, L.; Nilsson, B.; van Galen, P.; Metzeler, K.H.; Poeppl, A.; Ling, V.; Beyene, J.; et al. Stem cell gene expression programs influence clinical outcome in human leukemia. Nat. Med. 2011, 17, 1086-1093. [CrossRef]

70. Bullinger, L.; Ehrich, M.; Dohner, K.; Schlenk, R.F.; Dohner, H.; Nelson, M.R.; van den Boom, D. Quantitative DNA methylation predicts survival in adult acute myeloid leukemia. Blood 2010, 115, 636-642. [CrossRef]

71. Li, S.; Garrett-Bakelman, F.E.; Chung, S.S.; Sanders, M.A.; Hricik, T.; Rapaport, F.; Patel, J.; Dillon, R.; Vijay, P.; Brown, A.L.; et al. Distinct evolution and dynamics of epigenetic and genetic heterogeneity in acute myeloid leukemia. Nat. Med. 2016, 22, 792-799. [CrossRef] [PubMed]

72. Irish, J.M.; Hovland, R.; Krutzik, P.O.; Perez, O.D.; Bruserud, O.; Gjertsen, B.T.; Nolan, G.P. Single cell profiling of potentiated phospho-protein networks in cancer cells. Cell 2004, 118, 217-228. [CrossRef] [PubMed]

73. Bruserud, O.; Aasebo, E.; Hernandez-Valladares, M.; Tsykunova, G.; Reikvam, H. Therapeutic targeting of leukemic stem cells in acute myeloid leukemia-The biological background for possible strategies. Expert Opin. Drug Dis. 2017, 12, 1053-1065. [CrossRef] [PubMed] 
74. Pelletier, J.; Thomas, G.; Volarevic, S. Ribosome biogenesis in cancer: New players and therapeutic avenues. Nat. Rev. Cancer 2018, 18, 51-63. [CrossRef]

75. Wang, E.; Lu, S.X.; Pastore, A.; Chen, X.; Imig, J.; Chun-Wei Lee, S.; Hockemeyer, K.; Ghebrechristos, Y.E.; Yoshimi, A.; Inoue, D.; et al. Targeting an RNA-Binding Protein Network in Acute Myeloid Leukemia. Cancer Cell 2019, 35, 369-384. [CrossRef]

76. Delgado, M.D.; Albajar, M.; Gomez-Casares, M.T.; Batlle, A.; Leon, J. MYC oncogene in myeloid neoplasias. Clin. Transl. Oncol. 2013, 15, 87-94. [CrossRef]

77. Delgado, M.D.; Leon, J. Myc roles in hematopoiesis and leukemia. Genes Cancer 2010, 1, 605-616. [CrossRef]

78. van Riggelen, J.; Yetil, A.; Felsher, D.W. MYC as a regulator of ribosome biogenesis and protein synthesis. Nat. Rev. Cancer 2010, 10, 301-309. [CrossRef]

79. Grandori, C.; Gomez-Roman, N.; Felton-Edkins, Z.A.; Ngouenet, C.; Galloway, D.A.; Eisenman, R.N.; White, R.J. c-Myc binds to human ribosomal DNA and stimulates transcription of rRNA genes by RNA polymerase I. Nat. Cell Biol. 2005, 7, 311-318. [CrossRef]

80. Herter, E.K.; Stauch, M.; Gallant, M.; Wolf, E.; Raabe, T.; Gallant, P. snoRNAs are a novel class of biologically relevant Myc targets. BMC Biol. 2015, 13, 25. [CrossRef]

81. Derenzini, E.; Rossi, A.; Trere, D. Treating hematological malignancies with drugs inhibiting ribosome biogenesis: When and why. J. Hematol. Oncol. 2018, 11, 75. [CrossRef] [PubMed]

82. Bywater, M.J.; Poortinga, G.; Sanij, E.; Hein, N.; Peck, A.; Cullinane, C.; Wall, M.; Cluse, L.; Drygin, D.; Anderes, K.; et al. Inhibition of RNA polymerase I as a therapeutic strategy to promote cancer-specific activation of p53. Cancer Cell 2012, 22, 51-65. [CrossRef] [PubMed]

83. Stransky, L.A.; Forgac, M. Amino Acid Availability Modulates Vacuolar H+-ATPase Assembly. J. Biol. Chem. 2015, 290, 27360-27369. [CrossRef] [PubMed]

84. Zoncu, R.; Bar-Peled, L.; Efeyan, A.; Wang, S.; Sancak, Y.; Sabatini, D.M. mTORC1 senses lysosomal amino acids through an inside-out mechanism that requires the vacuolar H(+)-ATPase. Science 2011, 334, 678-683. [CrossRef] [PubMed]

85. Kobia, F.; Duchi, S.; Deflorian, G.; Vaccari, T. Pharmacologic inhibition of vacuolar H+ ATPase reduces physiologic and oncogenic Notch signaling. Mol. Oncol. 2014, 8, 207-220. [CrossRef] [PubMed]

86. Bernhard, S.M.; Seidel, K.; Schmitz, J.; Klare, S.; Kirsch, S.; Schrezenmeier, E.; Zaade, D.; Meyborg, H.; Goldin-Lang, P.; Stawowy, P.; et al. The (pro)renin receptor ((P)RR) can act as a repressor of Wnt signalling. Biochem. Pharmacol. 2012, 84, 1643-1650. [CrossRef]

87. Rothe, K.; Porter, V.; Jiang, X. Current Outlook on Autophagy in Human Leukemia: Foe in Cancer Stem Cells and Drug Resistance, Friend in New Therapeutic Interventions. Int. J. Mol. Sci. 2019, 20, 461. [CrossRef]

88. Zare-Abdollahi, D.; Safari, S.; Movafagh, A.; Ghadiani, M.; Tabarraee, M.; Riazi-Isfahani, S.; Gorji, S.; Keyvan, L.; Gachkar, L. Expression analysis of BECN1 in acute myeloid leukemia: Association with distinct cytogenetic and molecular abnormalities. Int. J. Lab. Hematol. 2016, 38, 125-132. [CrossRef]

89. Radwan, S.M.; Hamdy, N.M.; Hegab, H.M.; El-Mesallamy, H.O. Beclin-1 and hypoxia-inducible factor-1alpha genes expression: Potential biomarkers in acute leukemia patients. Cancer Biomark. 2016, 16, 619-626. [CrossRef]

90. Aasebø, E.; Bartaula-Brevik, S.; Hernandez-Valladares, M.; Bruserud, Ø. Vacuolar ATPase as a possible therapeutic target in human acute myeloid leukemia. Expert Rev. Hematol. 2018, 11, 13-24. [CrossRef]

91. Watson, A.S.; Riffelmacher, T.; Stranks, A.; Williams, O.; De Boer, J.; Cain, K.; MacFarlane, M.; McGouran, J.; Kessler, B.; Khandwala, S.; et al. Autophagy limits proliferation and glycolytic metabolism in acute myeloid leukemia. Cell Death Discov. 2015, 1. [CrossRef] [PubMed]

92. Rothe, K.; Lin, H.; Lin, K.B.; Leung, A.; Wang, H.M.; Malekesmaeili, M.; Brinkman, R.R.; Forrest, D.L.; Gorski, S.M.; Jiang, X. The core autophagy protein ATG4B is a potential biomarker and therapeutic target in CML stem/progenitor cells. Blood 2014, 123, 3622-3634. [CrossRef]

93. Piya, S.; Kornblau, S.M.; Ruvolo, V.R.; Mu, H.; Ruvolo, P.P.; McQueen, T.; Davis, R.E.; Hail, N., Jr.; Kantarjian, H.; Andreeff, M.; et al. Atg7 suppression enhances chemotherapeutic agent sensitivity and overcomes stroma-mediated chemoresistance in acute myeloid leukemia. Blood 2016, 128, 1260-1269. [CrossRef] [PubMed]

94. Sumitomo, Y.; Koya, J.; Nakazaki, K.; Kataoka, K.; Tsuruta-Kishino, T.; Morita, K.; Sato, T.; Kurokawa, M. Cytoprotective autophagy maintains leukemia-initiating cells in murine myeloid leukemia. Blood 2016, 128, 1614-1624. [CrossRef] 
95. Guo, W.; Jin, J.; Pan, J.; Yao, R.; Li, X.; Huang, X.; Ma, Z.; Huang, S.; Yan, X.; Jin, J.; et al. The change of nuclear LC3 distribution in acute myeloid leukemia cells. Exp. Cell Res. 2018, 369, 69-79. [CrossRef] [PubMed]

96. Buontempo, F.; McCubrey, J.A.; Orsini, E.; Ruzzene, M.; Cappellini, A.; Lonetti, A.; Evangelisti, C.; Chiarini, F.; Evangelisti, C.; Barata, J.T.; et al. Therapeutic targeting of CK2 in acute and chronic leukemias. Leukemia 2018, 32. [CrossRef] [PubMed]

97. Choi, Y.J.; Anders, L. Signaling through cyclin D-dependent kinases. Oncogene 2014, 33, 1890-1903. [CrossRef]

98. Saiki, Y.; Yamazaki, Y.; Yoshida, M.; Katoh, O.; Nakamura, T. Human EVI9, a homologue of the mouse myeloid leukemia gene, is expressed in the hematopoietic progenitors and down-regulated during myeloid differentiation of HL60 cells. Genomics 2000, 70, 387-391. [CrossRef]

99. Yin, B.; Delwel, R.; Valk, P.J.; Wallace, M.R.; Loh, M.L.; Shannon, K.M.; Largaespada, D.A. A retroviral mutagenesis screen reveals strong cooperation between Bcl11a overexpression and loss of the Nf1 tumor suppressor gene. Blood 2009, 113, 1075-1085. [CrossRef]

100. Jowsey, P.; Morrice, N.A.; Hastie, C.J.; McLauchlan, H.; Toth, R.; Rouse, J. Characterisation of the sites of DNA damage-induced 53BP1 phosphorylation catalysed by ATM and ATR. DNA Repair 2007, 6, 1536-1544. [CrossRef]

101. Drane, P.; Brault, M.E.; Cui, G.; Meghani, K.; Chaubey, S.; Detappe, A.; Parnandi, N.; He, Y.; Zheng, X.F.; Botuyan, M.V.; et al. TIRR regulates 53BP1 by masking its histone methyl-lysine binding function. Nature 2017, 543, 211-216. [CrossRef] [PubMed]

102. Kim, S.; Kim, S.; Rhee, K. NEK7 is essential for centriole duplication and centrosomal accumulation of pericentriolar material proteins in interphase cells. J. Cell Sci. 2011, 124, 3760-3770. [CrossRef] [PubMed]

103. Salem, H.; Rachmin, I.; Yissachar, N.; Cohen, S.; Amiel, A.; Haffner, R.; Lavi, L.; Motro, B. Nek7 kinase targeting leads to early mortality, cytokinesis disturbance and polyploidy. Oncogene 2010, 29, 4046-4057. [CrossRef] [PubMed]

104. Belham, C.; Comb, M.J.; Avruch, J. Identification of the NIMA family kinases NEK6/7 as regulators of the p70 ribosomal S6 kinase. Curr. Biol. 2001, 11, 1155-1167. [CrossRef]

105. Dalby, K.N.; Morrice, N.; Caudwell, F.B.; Avruch, J.; Cohen, P. Identification of regulatory phosphorylation sites in mitogen-activated protein kinase (MAPK)-activated protein kinase-1a/p90rsk that are inducible by MAPK. J. Biol. Chem. 1998, 273, 1496-1505. [CrossRef] [PubMed]

106. Sulzmaier, F.J.; Ramos, J.W. RSK isoforms in cancer cell invasion and metastasis. Cancer Res. 2013, 73, 6099-6105. [CrossRef]

107. Hatfield, K.J.; Hovland, R.; Øyan, A.M.; Kalland, K.H.; Ryningen, A.; Gjertsen, B.T.; Bruserud, Ø. Release of angiopoietin-1 by primary human acute myelogenous leukemia cells is associated with mutations of nucleophosmin, increased by bone marrow stromal cells and possibly antagonized by high systemic angiopoietin-2 levels. Leukemia 2008, 22, 287-293. [CrossRef]

108. Reikvam, H.; Hovland, R.; Forthun, R.B.; Erdal, S.; Gjertsen, B.T.; Fredly, H.; Bruserud, O. Disease-stabilizing treatment based on all-trans retinoic acid and valproic acid in acute myeloid leukemia-Identification of responders by gene expression profiling of pretreatment leukemic cells. BMC Cancer 2017, 17, 630. [CrossRef]

109. Geiger, T.; Cox, J.; Ostasiewicz, P.; Wisniewski, J.R.; Mann, M. Super-SILAC mix for quantitative proteomics of human tumor tissue. Nat. Methods 2010, 7, 383-385. [CrossRef]

110. Wisniewski, J.R.; Zougman, A.; Nagaraj, N.; Mann, M. Universal sample preparation method for proteome analysis. Nat. Methods 2009, 6, 359-362. [CrossRef]

111. Kulak, N.A.; Pichler, G.; Paron, I.; Nagaraj, N.; Mann, M. Minimal, encapsulated proteomic-sample processing applied to copy-number estimation in eukaryotic cells. Nat. Methods 2014, 11, 319-324. [CrossRef] [PubMed]

112. Aasebø, E.; Hernandez-Valladares, M.; Selheim, F.; Berven, F.S.; Brenner, A.K.; Bruserud, Ø. Proteomic Profiling of Primary Human Acute Myeloid Leukemia Cells Does Not Reflect Their Constitutive Release of Soluble Mediators. Proteomes 2018, 7, 1. [CrossRef] [PubMed]

113. Cox, J.; Mann, M. MaxQuant enables high peptide identification rates, individualized p.p.b.-range mass accuracies and proteome-wide protein quantification. Nat. Biotechnol. 2008, 26, 1367-1372. [CrossRef] [PubMed]

114. Cox, J.; Matic, I.; Hilger, M.; Nagaraj, N.; Selbach, M.; Olsen, J.V.; Mann, M. A practical guide to the MaxQuant computational platform for SILAC-based quantitative proteomics. Nat. Protoc. 2009, 4, 698-705. [CrossRef]

115. Cox, J.; Neuhauser, N.; Michalski, A.; Scheltema, R.A.; Olsen, J.V.; Mann, M. Andromeda: A peptide search engine integrated into the MaxQuant environment. J. Proteome Res. 2011, 10, 1794-1805. [CrossRef] 
116. Vizcaino, J.A.; Deutsch, E.W.; Wang, R.; Csordas, A.; Reisinger, F.; Rios, D.; Dianes, J.A.; Sun, Z.; Farrah, T.; Bandeira, N.; et al. ProteomeXchange provides globally coordinated proteomics data submission and dissemination. Nat. Biotechnol. 2014, 32, 223-226. [CrossRef]

117. Vizcaino, J.A.; Csordas, A.; del-Toro, N.; Dianes, J.A.; Griss, J.; Lavidas, I.; Mayer, G.; Perez-Riverol, Y.; Reisinger, F.; Ternent, T.; et al. 2016 update of the PRIDE database and its related tools. Nucleic Acids Res. 2016, 44, D447-D456. [CrossRef]

118. Tyanova, S.; Temu, T.; Sinitcyn, P.; Carlson, A.; Hein, M.Y.; Geiger, T.; Mann, M.; Cox, J. The Perseus computational platform for comprehensive analysis of (prote)omics data. Nat. Methods 2016, 13, 731-740. [CrossRef]

119. Arntzen, M.Ø.; Koehler, C.J.; Barsnes, H.; Berven, F.S.; Treumann, A.; Thiede, B. IsobariQ: Software for isobaric quantitative proteomics using IPTL, iTRAQ, and TMT. J. Proteome Res. 2011, 10, 913-920. [CrossRef]

120. Scholz, C.; Lyon, D.; Refsgaard, J.C.; Jensen, L.J.; Choudhary, C.; Weinert, B.T. Avoiding abundance bias in the functional annotation of post-translationally modified proteins. Nat. Methods 2015, 12, 1003-1004. [CrossRef]

121. Hulsen, T.; de Vlieg, J.; Alkema, W. BioVenn-A web application for the comparison and visualization of biological lists using area-proportional Venn diagrams. BMC Genom. 2008, 9, 488. [CrossRef] [PubMed]

122. Subramanian, A.; Tamayo, P.; Mootha, V.K.; Mukherjee, S.; Ebert, B.L.; Gillette, M.A.; Paulovich, A.; Pomeroy, S.L.; Golub, T.R.; Lander, E.S.; et al. Gene set enrichment analysis: A knowledge-based approach for interpreting genome-wide expression profiles. Proc. Natl. Acad. Sci. USA 2005, 102, 15545-15550. [CrossRef]

123. Hornbeck, P.V.; Zhang, B.; Murray, B.; Kornhauser, J.M.; Latham, V.; Skrzypek, E. PhosphoSitePlus, 2014: Mutations, PTMs and recalibrations. Nucleic Acids Res. 2015, 43, D512-D520. [CrossRef] [PubMed]

124. Linding, R.; Jensen, L.J.; Ostheimer, G.J.; van Vugt, M.A.; Jorgensen, C.; Miron, I.M.; Diella, F.; Colwill, K.; Taylor, L.; Elder, K.; et al. Systematic discovery of in vivo phosphorylation networks. Cell 2007, 129, 1415-1426. [CrossRef] [PubMed]

125. Szklarczyk, D.; Morris, J.H.; Cook, H.; Kuhn, M.; Wyder, S.; Simonovic, M.; Santos, A.; Doncheva, N.T.; Roth, A.; Bork, P.; et al. The STRING database in 2017: Quality-controlled protein-protein association networks, made broadly accessible. Nucleic Acids Res. 2017, 45, D362-D368. [CrossRef] [PubMed]

126. Shannon, P.; Markiel, A.; Ozier, O.; Baliga, N.S.; Wang, J.T.; Ramage, D.; Amin, N.; Schwikowski, B.; Ideker, T. Cytoscape: A software environment for integrated models of biomolecular interaction networks. Genome Res. 2003, 13, 2498-2504. [CrossRef]

127. Nepusz, T.; Yu, H.; Paccanaro, A. Detecting overlapping protein complexes in protein-protein interaction networks. Nat. Methods 2012, 9, 471-472. [CrossRef] [PubMed]

128. Andersson, L.C.; Nilsson, K.; Gahmberg, C.G. K562-Human Erythroleukemic Cell-Line. Int. J. Cancer 1979, 23, 143-147. [CrossRef] [PubMed]

129. Fajtova, M.; Babusikova, O. Immunophenotype characterization of hematopoietic stem cells, progenitor cells restricted to myeloid lineage and their leukemia counterparts. Neoplasma 2010, 57, 392-400. [CrossRef] [PubMed]

130. Consortium, E.P. An integrated encyclopedia of DNA elements in the human genome. Nature 2012, 489, 57-74. [CrossRef]

131. Langmead, B.; Salzberg, S.L. Fast gapped-read alignment with Bowtie 2. Nat. Methods 2012, 9, 357-359. [CrossRef] [PubMed]

132. Zhang, Y.; Liu, T.; Meyer, C.A.; Eeckhoute, J.; Johnson, D.S.; Bernstein, B.E.; Nusbaum, C.; Myers, R.M.; Brown, M.; Li, W.; et al. Model-based analysis of ChIP-Seq (MACS). Genome Biol. 2008, 9, R137. [CrossRef] [PubMed]

133. Heinz, S.; Benner, C.; Spann, N.; Bertolino, E.; Lin, Y.C.; Laslo, P.; Cheng, J.X.; Murre, C.; Singh, H.; Glass, C.K. Simple combinations of lineage-determining transcription factors prime cis-regulatory elements required for macrophage and B cell identities. Mol. Cell 2010, 38, 576-589. [CrossRef] [PubMed]

134. Korfanty, J.; Stokowy, T.; Chadalski, M.; Toma-Jonik, A.; Vydra, N.; Widlak, P.; Wojtas, B.; Gielniewski, B.; Widlak, W. SPEN protein expression and interactions with chromatin in mouse testicular cells. Reproduction 2018, 156, 195-206. [CrossRef] [PubMed]

135. Janus, P.; Szoltysek, K.; Zajac, G.; Stokowy, T.; Walaszczyk, A.; Widlak, W.; Wojtas, B.; Gielniewski, B.; Iwanaszko, M.; Braun, R.; et al. Pro-inflammatory cytokine and high doses of ionizing radiation have similar effects on the expression of NF-kappaB-dependent genes. Cell. Signal. 2018, 46, 23-31. [CrossRef] 
136. Janus, P.; Stokowy, T.; Jaksik, R.; Szoltysek, K.; Handschuh, L.; Podkowinski, J.; Widlak, W.; Kimmel, M.; Widlak, P. Cross talk between cytokine and hyperthermia-induced pathways: Identification of different subsets of NF-kappaB-dependent genes regulated by TNFalpha and heat shock. Mol. Genet. Genom. 2015, 290, 1979-1990. [CrossRef]

137. Wang, S.; Sun, H.; Ma, J.; Zang, C.; Wang, C.; Wang, J.; Tang, Q.; Meyer, C.A.; Zhang, Y.; Liu, X.S. Target analysis by integration of transcriptome and ChIP-seq data with BETA. Nat. Protoc. 2013, 8, 2502-2515. [CrossRef]

138. Huang, D.W.; Sherman, B.T.; Lempicki, R.A. Systematic and integrative analysis of large gene lists using DAVID bioinformatics resources. Nat. Protoc. 2009, 4, 44-57. [CrossRef]

139. Huang, D.W.; Sherman, B.T.; Lempicki, R.A. Bioinformatics enrichment tools: Paths toward the comprehensive functional analysis of large gene lists. Nucleic Acids Res. 2009, 37, 1-13. [CrossRef]

140. Kim, S.; Chen, J.; Cheng, T.; Gindulyte, A.; He, J.; He, S.; Li, Q.; Shoemaker, B.A.; Thiessen, P.A.; Yu, B.; et al. PubChem 2019 update: Improved access to chemical data. Nucleic Acids Res. 2019, 47, D1102-D1109. [CrossRef]

141. Schneider, C.A.; Rasband, W.S.; Eliceiri, K.W. NIH Image to ImageJ: 25 years of image analysis. Nat. Methods 2012, 9, 671-675. [CrossRef] [PubMed]

(C) 2020 by the authors. Licensee MDPI, Basel, Switzerland. This article is an open access article distributed under the terms and conditions of the Creative Commons Attribution (CC BY) license (http://creativecommons.org/licenses/by/4.0/). 